\title{
Am I outdated? The role of strengths use support and friendship opportunities for coping with technological insecurity
}

\author{
Tim M. Goetz *, Stephan A. Boehm \\ University of St.Gallen (HSG), Center for Disability and Integration, Rosenbergstrasse 51, CH-9000, St.Gallen, Switzerland
}

\section{A R T I C L E I N F O}

\section{Keywords:}

Conservation of resources

Technostress

Organizational resources

Strengths use

Workplace friendship

Occupational health

\begin{abstract}
A B S T R A C T
In the digital era, the prevalent integration of new technologies in work processes gives rise to employees' perceptions of technological insecurity. Such technology-induced strain poses new challenges to occupational health and safety and needs to be better understood in order to be prevented. Based on Conservation of Resources (COR) theory, we investigate to which extent the negative effect of technological insecurity on perceived health depends upon the availability of non-technology-related resources in the workplace. Specifically, we argue that employees who experience two key organizational resources, i.e. organizational support for strengths use and friendship opportunities, are better suited to cope with these modern forms of strain. We hypothesize that those resources reinforce each other in such way that employees' coping capabilities rise and health issues decrease. For hypothesis testing, time-lagged hierarchical moderated regression analysis is conducted. The study sample consists of 8019 German employees. Results support our assumption that accumulating resources create an intensified buffering effect, which surpasses the additive buffering effects of individual resources. Under the condition of high support for strengths use and high friendship opportunities, technological insecurity does no longer show a negative relationship with employees' time-lagged health. By using post-stratification weights, these results apply to 33.3 million employees in Germany having access to Information and Communication Technologies.
\end{abstract}

\section{Introduction}

Digitization is speeding up and it is accompanied by dramatic changes for the workforce. There is almost no day public press does not report about new technologies and their threats to existing jobs. Forecasts expect growth rates in worldwide spending on Information and Communication Technologies (ICTs) of double that of the global economy; leading to a total market opportunity of approximately $\$ 5.5$ trillion by 2020 (Businesswire, 2017). Further studies claim that almost $50 \%$ of all jobs are in high danger to be replaced by technological solutions in the future (Frey \& Osborne, 2017; 2018).

This development implies that new technologies will continue to change and penetrate work processes in the future. Technological changes will affect current demands in the workplace, cause recurring and reinforcing adaptation efforts for employees, add skill requirements or even turn employees' skills obsolete (Ayyagari, Grover, \& Purvis, 2011; Day, Scott, \& Kelloway, 2010; Fuglseth \& Søreb $\varnothing, 2014$; Gekara \& Thanh Nguyen, 2018; Ragu-Nathan, Tu, Tarafdar, Ragu-Nathan, 2008; Wang, Shu, \& Tu, 2008). Most likely, employees will experience increased levels of stress and strain due to increasing ICT demands in the workplace (i.e. "technostress", see Ayyagari et al., 2011; Ragu-Nathan et al., 2008; Weil \& Rosen, 1997). Due to those developments, the European Agency for Safety and Health at Work (European Agency for Safety and Health at Work (EU-OSHA), 2018, p.7) highlights that "digit [ization] [...] opens the door to an increase in [occupational safety and health] challenges, in particular of an ergonomic, organizational and psychosocial nature, that need to be better understood and managed."

In Information Systems (IS) literature, various studies have examined the negative effects of ICT-related stressors, such as on job-related, IS use related and well-being related outcomes (see Ayyagari et al., 2011; D'Arcy, Herath, \& Shoss, 2014; Tarafdar, Tu, Ragu-Nathan, \& Ragu-Nathan, 2007). Other studies focused on the boundary conditions of those relationships, such as technology self-efficacy and competence (Tarafdar, Pullins, \& Ragu-Nathan, 2015), ICT exposure control (Galluch, Grover, \& Thatcher, 2015), personality traits (Srivastava, Chandra, \& Shirish, 2015), ICT involvement facilitation (Ragu-Nathan et al., 2008), Technical support provision (Ragu-Nathan et al., 2008), ICT literacy facilitation (Ragu-Nathan et al., 2008) and training interventions

\footnotetext{
* Corresponding author.

E-mail addresses: tim.goetz@unisg.ch (T.M. Goetz), stephan.boehm@unisg.ch (S.A. Boehm).
} 
(Soucek \& Moser, 2010). Nonetheless, in line with recently published reviews on technostress (e.g. Tarafdar, Cooper, \& Stich, 2017), we argue that the IS literature on technostress is still limited in four important ways: First, prior research does not offer a sound theoretical explanation or framework to explore the effects of technostress on outcomes. Particularly, prior studies did not incorporate established theoretical explanations from outside the IS field, e.g. from psychological stress literature. Second, key stressors in the technostress literature and their respective effects on the health of employees are still understudied. One of those variables is technological insecurity (Ragu-Nathan et al., 2008; Tarafdar et al., 2007). It covers stress and strain associated with feelings of potential job loss due to ICT-related changes in the workplace (Ragu-Nathan et al., 2008). Third, prior research did not yet examine the effects of ICT-related stressors in the presence of supportive, non-technology-related organizational resources. Such resources could help employees to overcome ICT-induced stress and strain by enhancing coping capabilities. Fourth, previous studies mostly rely on rather small and isolated samples to examine the effects of ICT-related stressors which strongly limits their external validity.

To jointly address those research gaps, this study integrates Conservation of Resources (COR) theory as one of the most influential psychological stress theories with IS-related work on technostress. Further, we examine how two non-technology-related organizational conditions influence the relationship between employees perceived technological insecurity and their general health perception. To do so, we collected data from 8'019 employees in Germany, which can be statistically weighted to be representative for 33.3 million employees in the respective workforce. Based on COR theory, our central argument is that organizational conditions apart from the IS-related environment can serve as important resources that increase employees' coping capabilities with strain. This reduces the negative effect of technological insecurity on employees' health perceptions.

Specifically, we argue that two non-technology-related organizational resources are of particular relevance for employees in insecure and/or unstable working environments because they individually induce feelings of appraisal by and belonging to an organization: (a) organizational support for strengths use (Keenan \& Mostert, 2013; van Woerkom, Bakker, \& Nishii, 2016) and (b) friendship opportunities in the workplace (Morgeson \& Humphrey, 2006; Sims, Szilagyi, \& Keller, 1976). Organizational support for strengths use covers "employees' beliefs concerning the extent to which their employer actively supports them in applying their personal strengths at work" (van Woerkom et al., 2016, p. 142). This increases employees' actual use of their strengths at work and induces feelings of being valued due to own individual capabilities (Biswas-Diener, Kashdan, \& Minhas, 2011; van Woerkom et al., 2016).

Next, friendship opportunities in the workplace are a key element for the informal structure of organizations (Barney, 1985), which can increase the actual friendship formation among employees (Richey \& Richey, 1980; Tokuno, 1986). Friends enable to provide and receive assistance and emotional support to and from others. This can encourage positive emotions in the workplace such as trust, respect, support, and security (Chiaburu \& Harrison, 2008; Colbert, Bono, \& Purvanova, 2016; Foote, 1985; Grant, 2008; Spreitzer, 1995). We further argue that support for strengths use and friendship opportunities play together and reinforce each other by accumulating to higher resources levels (Hobfoll, 2011). This interaction of resources further increases one's coping capabilities and reduces stress and strain caused by technological insecurity.

Taken together, this study makes four primary contributions to the literature. First, we follow the call by Tarafdar et al. (2017) and provide a cross-disciplinary contribution by combining IS research on technostress with non-IS research on psychological stress (i.e., COR theory). By doing so, we open up a new research direction to adequately examine the impact of technostress on employees. Second, we provide theoretical and empirical support that technological insecurity is an important, yet understudied variable in the technostress literature that can negatively affect the perceived health of employees across an entire workforce. Third, we show that two non-technology-related organizational resources, i.e. support for strengths use and friendship opportunities, are important for employees in order to successfully cope with ICT-related stressors. This "interdisciplinary lens" on preventing and dealing with technostress broadens the existent research focus which has mainly focused on the role of boundary conditions directly related to ICTs (e.g. Technical support provision, ICT involvement facilitation, ICT equipment or ICT training). And fourth, we argue and empirically demonstrate that our results have high external validity and are robust with respect to multiple controls. By using post-stratification weights, the results apply to approximately 33.3 million employees in Germany who are 18 years or older and have access to internet-enabled ICTs.

\section{Theory and hypotheses}

Our central argument is that organizational resources, particularly organizational support for strengths use and friendship opportunities, help to decrease the negative effect of strain caused by technological insecurity concerns, and thus, increase employees' health perceptions. An overview of the hypothesized model is shown in Fig. 1.

\subsection{Conservation of Resources Theory}

Conservation of Resources Theory (COR; Hobfoll, 1989) is one of the most influential theories in explaining stress. Resources' are defined as objects (e.g., car, house), conditions (e.g., marriage, employment), energies (e.g., time, money), and personal characteristics (e.g., key skills, self-esteem) that are centrally valued by humans, are the major focus of the theory (Hobfoll, Freedy, Green, \& Solomon, 1996; recommended reading about resources: Halbesleben, Neveu, Paustian-Underdahl, \& Westman, 2014; Krohne, 2002; ten Brummelhuis \& Bakker, 2012). The psychological processes that motivate people to maintain and/or attain those resources explain how people react to everyday stressors in their environment and how this affects their respective well-being.

In its core, COR theory attempts to explain much of human behavior, respectively stress, from an evolutionary approach to resources. For instance, its rationale is largely derived from the notions of an "evolutionary-based built-in and powerful bias [of humans] to overweight resource loss and underweight resource gain [...] [and the] evolutionary need to acquire and conserve resources for survival" (Hobfoll, Halbesleben, Neveu, \& Westman, 2018, p. 104). Accordingly, COR theory's basic tenet is that "individuals [...] strive to obtain, retain, foster, and

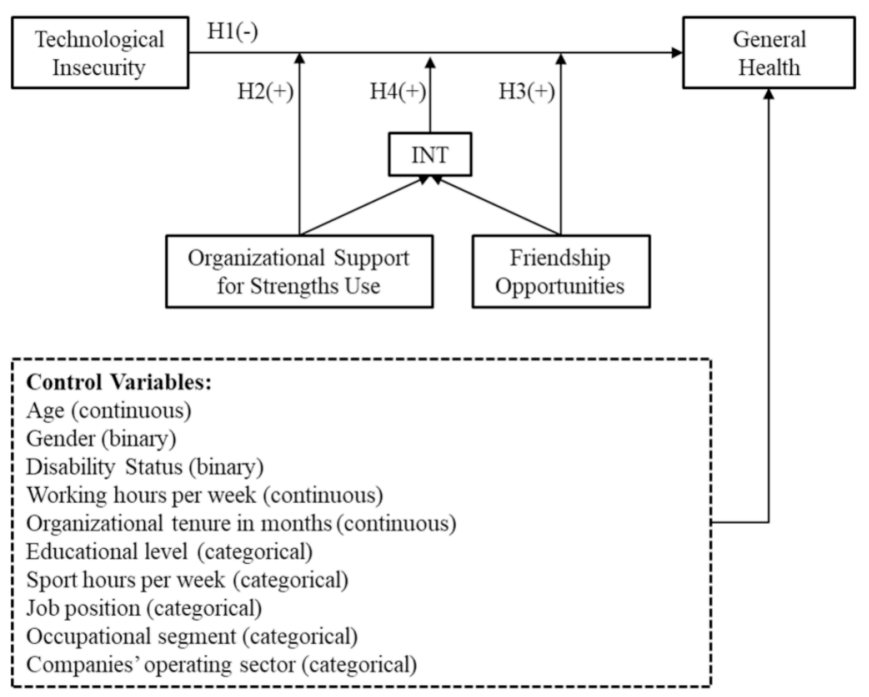

Fig. 1. Overview of Model and Hypothesis under investigation. 
protect resources" (Hobfoll et al., 2018, p. 104) and that stress arises when those resources are in danger to be depleted or are depleted (Hobfoll, 2002). Situations or events are perceived as 'stressful', i.e., causing strain, when individuals commonly associate those with potential or actual loss of the resources. This, in turn, may have detrimental effects on well-being.

COR theory has been constantly debated, applied, and modified since its first publication by Hobfoll (1989). This resulted in a compilation of individual principles and corollaries that together form the basis of today's COR theory (recommended readings for more detail: Halbesleben et al., 2014; Hobfoll et al., 2018; ten Brummelhuis \& Bakker, 2012). The applied tenets in this study are explained below.

First, the primacy of (resource) loss principle states that the detrimental effects of the loss of resources on individuals are disproportionately greater compared to the beneficial effects of the equivalent gain of resources. This also implies that resource loss "not only is more powerful than resource gain in magnitude but also tends to affect people more rapidly and at increasing speed over time" (Hobfoll et al., 2018, p. 105). Second, the resource investment principle describes that individuals "must invest resources to protect against resource loss, recover from losses, and gain resources" (Hobfoll et al., 2018, p. 105). This suggests that individuals engage in a direct replacement, e.g., replacing lack of income with savings, and indirect investment processes of resources, e.g., using time and money to increase key skills necessary to stay competitive in the workplace environment. Third, the gain paradox principle states that the importance of resource gains increases especially in times when resource loss is very likely or the resources are in high danger of depletion (Hobfoll, 2002; Hobfoll et al., 2018). Fourth, Corollary 1 states that the possession and the lack of resources are crucial factors in an individual's vulnerability and resilience, mainly assuming that "those with greater resources are less vulnerable to resource loss and more capable of resource gain" (Hobfoll et al., 2018). The contrary applies to individuals who lack resources.

Applying those rationalities, COR theory must be differentiated from other stress theories, especially Lazarus and Folkman's (1984) stress-appraisal theory. In sum, the stress-appraisal theory postulates that the extent of the effects of stressful situations depends on one's perception, i.e., 'appraisal' of these situations as stressful. It even assumes that there is no such thing as environmentally produced stress without the appraisal of the individual (Lazarus \& Folkman, 1984, p. 19). In the first place, the stress-appraisal theory implicitly considers the occurrence of stress to solely depend on an individual's appraisal of the situation which might lead to certain problematic conclusions in certain contexts.

For instance, in the context of a criminal act, stress would emerge in response to the victims' perception of the event to be stressful. As such, addressing the situation would be a matter of the victim who would need to adjust his/her appraisals (Hobfoll et al., 2018) rather than the matter of the criminal act itself. As this is only one drawback of former stress theories (for a detailed discussion see Hobfoll, 1989; Hobfoll et al., 2018), Hobfoll (1989) formulated the COR theory to provide a more appropriate and testable understanding of coping and stress.

Although COR theory does not deny subjective appraisal, it puts much more emphasis on the objectivity of stressful events (Hobfoll, 1989; Hobfoll et al., 2018). It follows the notion that stressful events contain objectively stressful elements "that are shared within a culture and have a common level of impact" (Hobfoll et al., 2018, p. 104). Although subjective perceptions might have an influence, COR theory states that objective elements will be the determining factors in explaining the effects of stressful events on any outcome.

In this study, we assumed that perceptions of technological insecurity can be regarded as a commonly stressful situation that contains negative objective elements for employees. The rationalities behind this assumption are outlined in the following section.

\subsection{Technological insecurity and health}

One special form of job insecurity that is on the rise is the so-called technological insecurity (Tarafdar et al., 2007). More than 30 years ago, clinical psychologist Craig Brod's (1984) already described, in his book "Technostress: The Human Cost of the Computer Revolution," a term called technostress as "a modern disease of adaptation caused by an inability to cope with the new computer technologies in a healthy manner" (p.16). Weil and Rosen (1997) adjusted this notion by including "any negative impact on attitudes, thoughts, behaviors, or body physiology that is caused either directly or indirectly by technology" (p.5). Since Brod's (1984) book, decades of irresistible enthusiasm to incorporate technologies have passed.

To date, ICTs are the most dominant technologies in the workplace because they provide high efficiency and productivity opportunities for organizations (Srivastava et al., 2015). However, they also change and shape organizational structures, working processes, and interactions between individuals inside and outside of organizations (Ayyagari et al., 2011). According to those persistent change processes, employees constantly need to learn new skills as well as to adapt to new work processes and increased capabilities of ICTs in performing complex tasks. This may lead to doubts about one owns' ability to keep up with the rising workplace demands through ICTs and/or to worries about being replaced in the future (Ayyagari, Grover, \& Puris, 2011; Day et al. 2010; Fuglseth \& Sørebø, 2014; Ragu-Nathan et al., 2008; Wang et al., 2008). In other words, technological insecurity actually focuses on perceived threat of losing the job due to technologies or also to other people, e.g., colleagues who possess a better knowledge or understanding of those technologies (Fuglseth \& Søreb $\varnothing$, 2014; Ragu-Nathan et al., 2008; Srivastava et al., 2015).

Therefore, technological insecurity links technological reasons with concerns about ones' job security. In line with COR theory, this means that when employees face increased technological insecurity, they commonly associate technologies with being a threat to actual resources, i.e., 'job insecurity' or 'employment' (Hobfoll et al. 1996; Krohne, 2002), which may lead to strain (Hobfoll, 1989). For example, an employee (e.g., a project manager) is confronted with continuous and/or radical changes in the technological environment of the organization. Hence, he/she shows high perceptions of technological insecurity (e.g., fear of being replaced in the future due to technological solutions that make ones' skills obsolete). Thus, individuals commonly associate this situation with an actual or potential loss of their current job (position), also called 'job insecurity.'

Job insecurity is generally defined as the subjective perception of being threatened by job loss and concerns about the continued job existence in the future (Klandermans \& van Vuuren, 1999; Mohr, 2000). Several studies have shown a link of job insecurity with increased stress and decreased well-being and health (Abildgaard, Nielsen, \& Sverke, 2018; De Jong et al., 2016; De Witte, Pienaar, \& De Cuyper, 2016; Hellgren \& Sverke, 2003; Wiezer et al., 2011). In particular, negative effects of job insecurity on both psychological well-being (e.g., depression), somatic health (e.g., high blood pressure), and general self-rated health have been established (Ibrahim, Smith, \& Muntaner, 2009; Kim, Kim, Park, \& Kawachi, 2008; Kirves, De Cuyper, Kinnunen, \& Nätti, 2011; Virtanen, Janlert, \& Hammarström, 2011). Therefore, job insecurity has been shown to have a major influence on health.

Therefore, as technological insecurity reflects an individuals' perception of being threatened in ones' job security or employment due to technologies, it is expected to be a common and objectively perceived stressful situation for employees. Nevertheless, the effect of technological insecurity on individuals' health has, to our knowledge, never been studied from a psychological stress perspective. Thus, the IS literature runs the risk of neglecting relevant findings of decades of research in the field of psychological stress. Hence, in line with COR theory's primacy of (resource) loss principle (Hobfoll, 1989; Hobfoll et al., 2018), we expect technological insecurity to cause actual strain manifested in a decreased 
assessment of one's general health perception. Therefore, we hypothesize:

Hypothesis 1. Technological Insecurity is negatively related to employees' perceived general health.

\subsection{Moderating effect of organizational support for strengths use}

As initially outlined, COR theory provides further rationalities about resource processes, which explain the coping of individuals in stressful situations. As stated in Corollary 1, people "with greater resources are less vulnerable to resource loss and more capable of resource gain" (Hobfoll et al., 2018, p. 105) because they are argued to be better suited for dealing with stressful situations (Hobfoll, 2002). In line with the resource investment principle (Hobfoll et al., 2018), a greater set of resources allows them to execute resource replacement processes when being confronted with resource losses, and thus, reduce strain (Hobfoll, 2002). Therefore, this rationality implies that individuals may actually use existing resources in order to induce coping processes for both actual and potential resource losses. For example, individuals may be able to invest energy resources (e.g. time) in the development of personal resources (e.g. new skills) to protect against potential losses of condition resources (e.g. employment) in the future.

Following the theoretical assumptions of COR theory, organizations may provide or emphasize special environmental conditions (organizational resources), that direct and energize employees' behavior and resources (Gagné \& Deci, 2005) to better cope with stressful conditions. One non-technology-related organizational resource, expected to be of particular relevance in stressful conditions of technological insecurity, is organizational support for strength use (Keenan \& Mostert, 2013). It has been shown that if individuals perceive their organizational environment to be supportive in terms of encouraging the use of their individual strengths, they are less likely to be negatively affected by strain experienced by stressful job conditions (van Woerkom et al., 2016). This form of organizational support relies on previous research showing that actual strength use leads to positive effects on the users' stress levels and well-being (Forest, Mageau, Crevier-Braud, Bergeron, Dubreuil, \& Lavigne; 2012; Senf \& Liau, 2013). Hence, it is argued that instead of focusing on the identification and correction of particular weaknesses of employees (Buckingham, 2005), organizations should rather enable and support the use of employees' existing strengths at work (Luthans \& Youssef, 2007). This organizational support then leads to increased levels of actual strengths use in the workplace. It is argued that enabling employees to perform tasks that capitalize on their individual strengths, these employees experience "higher levels of self-esteem as a result of feeling valued for their unique worth and experiences" (van Woerkom e al., 2016, p. 143). This may act as an important counterbalancing resource to the decreased self-confidence in one's worth for the company caused by experienced technological insecurity (Ayyagari et al., 2011). Furthermore, when employees perceive to be supported in doing what they are good at, this inherently covers freedom to behave more in line with their authentic selves and perform at ones' personal best according to one's individual habits (Wood, Linley, Maltby, Kashdan, \& Hurling, 2011). This may further stimulate their personal growth and development (Dollard \& Bakker, 2010; Peterson \& Seligman, 2004), decrease strain and increase performance and happiness levels (Forest et al., 2012; Govindji \& Linley, 2007; Seligman, Steen, Park, \& Peterson, 2005).

Therefore, when being supported to use one's individual strengths, employees experience the appreciation by the organization of one's abilities and thus profit from increased resource levels (e.g. personal resources: self-esteem, et cetera). Higher resource levels then further increase one's coping capabilities with strain (e.g. caused by the fear to loose one's job due to any technological solution). Hence, we argue that organizational support for strengths use acts as valuable resource in the workplace, which increases the coping capabilities of employees according to strain caused by the exposure to technological insecurity concerns. In this manner, in line with COR theory, organizational support for strength use is expected to decrease the negative effects of technological insecurity on one's general health perception. Therefore, we hypothesize the following:

Hypothesis 2. Organizational support for strengths use moderates the relationship between technological insecurity and general health such that the negative relationship between the two is weaker when organizational support for strengths use is higher.

\subsection{Moderating effect of friendship opportunities}

Moreover, friendship opportunities are expected to inhere high relevance in the ICT-related workplace context at hand. Fundamentally, the need to build social ties with others is one of the most central needs of human beings (Hobfoll et al., 2018). Strong social relationships to one another, often termed as friendships, provide several positive functions for the people involved such as, having a listener, someone who understands one's problems, receiving valuable advice, guidance, acceptance, and a sense of belonging to a social group (Richey \& Richey, 1980; Tokuno, 1986; Weiss, 1974). Those interpersonal encounters increase peoples' self-esteem and well-being (Hartup \& Stevens, 1997). Further, stable friendships enable opportunities to expand one's own social network by getting in closer contact with the people in the social network of a friend, subsequently profiting from aggregated benefits of more friendships (Buote et al., 2007).

Due to the fact, that most people spend a significant amount of time at work, it is not surprising that friendships play a crucial role in the workplace. This notion is supported by several studies showing the positive relation of workplace friendships with, e.g. job satisfaction, involvement, motivation, supportive and innovation climate, and productivity (Berman, West, \& Richter, 2002; Crabtree, 2004; Nielsen, Jax, \& Adams, 2000; Sias, Heath, Perry, Silva, \& Fix, 2004; Solano, 1986; Synder \& Smith, 1986). This is in line with recent findings by Colbert, Bono, and Purvanova (2016) who identify friendships in the workplace to be "the most important predictor of positive emotions at work" (p. 1215) and further highlight its importance for the individual and organizations, respectively.

From an organizational point of view, it is valuable that employees build friendships at work in order to capitalize on those benefits. Hence, an organization can design the workplace environment in a way that allows employees to participate in organizational processes and activities. Thus, enabling more social contact and communication with others, and subsequently strengthening the opportunities to develop friendships in the workplace (Ragins \& Dutton, 2007; Riordan \& Griffeth, 1995; Song, 2006). Those friendship opportunities (Morgeson \& Humphrey, 2006; Sims et al., 1976) are examined as an important antecedent for actual workplace friendships (Nielsen et al., 2000; Sias \& Cahill, 1998). This implies that the perception of employees about the extent the workplace environment provides adequate friendship opportunities is an important organizational job resource. It increases one's capabilities to lower stress levels by helping employees to cope with demanding situations, which further increases one's health perceptions (Berman et al., 2002; Buote et al., 2007; Ragins \& Dutton, 2007).

Hence, in the context of employees facing technological insecurity, providing adequate friendship opportunities (as antecedent for actual friendship formations) may increase employees' resources by helping to share one's individual uncertainty about the job-related future with peers. This subsequently buffers the negative strain effects by mutually received social support among friends. Therefore, friendship opportunities are assumed to increase one's possibilities to receive social support, share honest views with peers about one's uncertainty and perceptions of job threats caused by technology. This makes employees more likely to perceive oneself as an integrated element of the 
organization that will not be replaced, which ultimately reduces the impact of strain caused by technological insecurity on one's health perception. Hence, we hypothesize:

Hypothesis 3. Friendship opportunities moderates the relationship between technological insecurity and general health such that the negative relationship between the two is weaker when friendship opportunities are higher.

\subsection{Organizational resource reservoirs: strength use support and friendship opportunities}

As outlined, both organizational resources are individually expected to be valuable in enhancing coping capabilities with strain caused by technological insecurity. This roots mainly on the notion of COR theory's primacy of (resource) loss principle and Corollary 1 (Hobfoll et al., 2018). Together, they say that higher resource levels make employees less vulnerable to stressful conditions (Corollary 1 ) leading to less actual strain, and that the loss of resources takes place with a disproportionately high (negative) effect on individuals. Thus, resource losses are more salient than resource gains (Hobfoll, 2002, Hobfoll et al., 2018).

Further following these notions, when employees perceive to be provided with more types of resources, those individual resources accumulate to higher resource levels. Higher resource levels then enable to experience less strain caused by stressful conditions, which leads to less resource losses as a result of the coping process. In turn, decreased resource losses and strain leads to a disproportionate reduction of the associated negative impact on the individual, i.e. on one's health assessment. Therefore, we expect the mitigating role of resources to be higher when individuals are in possession of both resources simultaneously, meaning, being able to use both their strengths and develop social ties in form of friendships in the workplace.

Further, following the notion of COR theory's gain paradox principle, the effect of resource gains on individuals becomes particularly salient when resources are in danger to be depleted, or actually deplete (Hobfoll, 2002). This implies that higher resources unfold its true potential when employees perceive being confronted with high demanding conditions. Hence we additionally expect that especially in times of high stressful conditions (e.g. high technological insecurity), when job resources are in great danger of depletion, employees benefit the most from higher accumulated resource reservoirs. This is coherent, because particularly in situations when employees experience high stress caused by technological insecurity (e.g. in form of perceptions of not being able to adequately adapt to ongoing or expected technological changes; having actual fear to be replaced by technologies), employees may request and benefit the most from positive work experiences and feelings of appreciations caused by using their strengths and receiving emotional support from colleagues.

For example, again, imagine an employee (e.g. a project manager) with perceptions of technological insecurity that is confronted with continuous technological changes in the organization and therefore having high perceptions of technological insecurity (e.g. fear of being replaced by technologies that make one's skills obsolete). But, imagine, that the employee is additionally supported by the organization to use and foster the individual strengths (e.g. financial forecasting) and is provided with friendship opportunities in the workplace. By applying his individual strengths, this employee will perform tasks with unique value which provides him with higher security to not fall into disuse in the future. Additionally, he performs routine tasks on a high level with less effort. Thus, using one's strengths encourages higher self-esteem while performing at one's personal best and feelings of being valued by the organization due to the individual abilities. This leaves the employee with more time, energy and attitude towards work to cope with the demanding situation (e.g. by investing time and energy in improving key skills to foster the employment position). In addition, the employee will be able to exchange thoughts and information on the relevance of technological changes with peers from other organizational areas and from peers in the specific field of financial forecasting. This leaves the employee with feelings of being an integral part of the social/ informal organizational environment, not being confronted with the technological insecurity just on its own. This informal environment allows to receive mutual emotional support amongst peers, which is particularly valuable when feeling insecure. As a result, this decreases the impact of stress caused by perceptions of high technological insecurity on the employee's health perception.

Therefore, employees will experience an accumulated level of organizational resources when being provided with both organizational support for strengths use and friendship opportunities simultaneously. The higher resource levels buffer the impact of stress caused by perceptions of technological insecurity on the employee's health perception at a disproportionally higher level. In addition, the higher resource levels are expected to be particularly valuable when the employee encounters stressful situations. Thus, the employee is encouraged to make the most out of those resources provided in times of high technological insecurity. In this particular situation, the resources show an accumulated buffering effect on the negative effect of technological insecurity on health. Hence, in line with COR theory, we hypothesize:

Hypothesis 4. There is a three-way interaction among technological insecurity, organizational support for strengths use and friendship opportunities in explaining general health. The negative relationship between technological insecurity and general health is weaker when both organizational support for strengths use and friendship opportunities are high and stronger when both organizational support for strengths use and friendship opportunities are low than in any other combination of organizational support for strengths use and friendship opportunities.

\section{Methods}

\subsection{Data collection and sample}

To test our hypotheses, we collected a representative data set for the German labor force by instructing a German market research institute with the data collection process. In doing so, we only surveyed participants with an age of 18 years or older, who are currently employed and have access to internet-enabled communication technologies. Hence, all participants of the survey are registered panel members who agreed to participate in online surveys and are rewarded for their participation by points which can be converted into a real currency. To ensure high data quality, the research institute thoroughly checks for and excludes participants who are found to manipulate the survey (e.g. multiple participation or click-through behavior). To reduce single-source bias, twowave survey data were collected. The survey versions were translated to German by professional translators following a double-blind backtranslation procedure to ensure semantic equivalence with the original English items (Schaffer \& Riordan, 2003). The two surveys were carried out at a 9-month interval, resulting in 8019 and 8004 respondents, respectively. Being able to track each participant by a specific ID enabled us to identify an overlap sample of 4754 respondents having participated in both survey waves. Therefore, attrition rate is $40.7 \%$.

To take missing values of the model variables into account, we conducted chained multiple imputation by using the mi impute chained command in Stata software version 15 (StataCorp. 2017). We chose chained imputation over multi-variate normal imputation (mvn), because variables with missing values are not solely of continuous nature and violate the normality assumption of mvn. All variables in the model are included in the imputation model. We imputed continuous variables using linear regression models, binary variables using logistic regression models, ordinal variables using ordered logistic regression models and categorical variables using multinomial logistic regression models. Although some continuous variables were skewed, they were imputed on the raw scale without transformation, irrespective of their 
Table 1

Means, Standard Deviations, and Standardized Factor Loadings of the main study items.

\begin{tabular}{|c|c|c|c|c|c|}
\hline \multicolumn{6}{|l|}{ Measurement items of main study variables } \\
\hline Items & M & SD & $\mathrm{N}$ & Load. & Source \\
\hline \multicolumn{6}{|l|}{ Technological insecurity $(\mathrm{N}=8019, \mathrm{~T} 1)$} \\
\hline I: "I feel constant threat to my job security due to new technologies." & 1.80 & .98 & 8019 & (fixed) & \multirow{4}{*}{$\begin{array}{l}\text { Tarafdar, Tu, Ragu-Nathan,\& Ragu-Nathan } \\
\text { (2007) }\end{array}$} \\
\hline II: "I have to constantly update my skills to avoid being replaced." & 2.43 & 1.17 & 8019 & .90 & \\
\hline III: "I am threatened by coworkers with newer technology skills." & 1.75 & .94 & 8019 & 1.09 & \\
\hline IV: "I do not share my knowledge with my coworkers for fear of being replaced." & 1.59 & .90 & 8019 & .89 & \\
\hline \multicolumn{6}{|l|}{ Org. Strength use support $(\mathrm{N}=7861, \mathrm{~T} 1)$} \\
\hline I: "My organization gives me the opportunity to do what I am good at." & 3.71 & 1.03 & 7987 & (fixed) & \multirow[t]{5}{*}{ Keenan and Mostert (2013) } \\
\hline II: "My organization allows me to use my talents." & 3.59 & 1.07 & 7973 & 1.02 & \\
\hline III: "My organization ensures that my strengths are aligned with my job tasks." & 3.57 & 1.05 & 7936 & .99 & \\
\hline IV: "My organization allows me to do my job in a manner that best suits my strong points." & 3.62 & 1.03 & 7965 & .99 & \\
\hline \multicolumn{5}{|l|}{ Friendship opportunities $(\mathrm{N}=7808, \mathrm{~T} 1)$} & \\
\hline I: "I have the opportunity to develop close friendships in my job." & 3.09 & 1.15 & 7917 & (fixed) & Morgeson \& Humphrey (2006), adapted from \\
\hline II: "I have the chance in my job to get to know other people." & 3.84 & 1.16 & 7930 & 1.08 & \multirow[t]{2}{*}{ Sims, Szilagyi, \& Keller (1976) } \\
\hline III: "I have the opportunity to meet with others in my work." & 3.61 & 1.19 & 7953 & 1.37 & \\
\hline \multicolumn{6}{|l|}{ General Health $(N=7901, T 2)$} \\
\hline $\begin{array}{l}\text { "When indicating the best conceivable health condition with } 10 \text { points and the worst with } \\
0 \text { points: How would you assess your current health condition?" }\end{array}$ & 7.88 & 1.81 & 7901 & - & $\begin{array}{l}\text { Adapted from Tuomi, Ilmarinen, Jakhola, } \\
\text { Katajarinne, \& Tulkki (1998) }\end{array}$ \\
\hline
\end{tabular}

Note. Mean, SDs, and Loadings of items shown for Confirmatory Factor Analyses in the unimputed, original data set with listwise deletion as commands mi impute and sem are not jointly available in Stata. All items were measured on a 5-point Likert scale with 1 (completely disagree) to 5 (completely agree), except the General Health item, which is measured on a 11-point Likert like scale with 0 (worst possible) to 10 (best possible). All loadings (coefficients) are significant with $\mathrm{p}<.01$.

distribution (Lee \& Carlin, 2017; von Hippel, 2013). Hence, we did not constrain the imputation values to a specific range of values (e.g. Likert scale range) - "although this imputation method results in some implausible values, it appears to be the most consistent method with low bias and reliable coverage in repeated sampling of missingness, irrespective of the amount of skewness in the data." (Rodwell, Katherine, Romanuik, \& Carlin, 2014, p. 10). To take care of missing values in the dependent variable due to dropout (potential 'attrition bias', see Asendorpf, Van De Schoot, Denissen, \& Hutteman, 2014), we also imputed the dependent variable (second survey period) by adding the same variable from the first survey period as an auxiliary variable in the imputation model (Enders, 2010; Johnson \& Young, 2011; White, Royston, \& Wood, 2010). This procedure leads to more accurate and stable estimates when the auxiliary variable is strongly correlated with the dependent variable, e.g. $>0.5$ (Enders, 2010; Johnson \& Young, 2011). Herein, the observed correlation is 0.66 , and therefore fits this criterion. In total, 50 datasets were imputed, being in line with the rule of thumb provided by White et al. (2010), as the number of imputed data sets surpasses the maximum percentage of missing cases in one variable (here: $41.3 \%$ in outcome variable). All variables were imputed on the item level. In doing so, all observations of the first survey period, 8019 in total, are used for hypothesis testing.

After multiple imputation, the final study sample consists of 8019 observations. Herein, the age of the respondents ranged from 18 to 77 years, with an average of 44.3 . Hence, the sample consisted of 3.922 women and 4.097 men (i.e. $51.1 \%$ were male). Of all respondents, $31.4 \%$ hold a university degree, $21.0 \%$ a higher education entrance qualification, $39.3 \%$ a secondary school leaving certificate, and $8.4 \%$ hold a lower vocational background. On average, the contractual working hours of the respondents are $35.1 \mathrm{~h}$ per week and the mean organizational tenure is 11.4 years. Additionally, $11.5 \%$ do have an officially labeled disability. By using sample weights, the study sample can be weighted to be representative for 33.3 million employees of at least full age in Germany and having access to internet-enabled ICTs. ${ }^{1}$

\footnotetext{
${ }^{1}$ Structural representativeness is established by comparing the distribution of key demographics in the data sample at hand with the distribution in the statistical population. The participants are weighted so that the weighted data sample has the same distribution as in the statistical population. For this procedure, we acquired access to 'best for planning' (b4p, 2016) data. 'b4p' are statistical population data for the German workforce - regularly collected by the 'Gesellschaft für integrierte Kommunikationsforschung' (GIK). For further information, please contact the authors.
}

\subsection{Measures}

Unless otherwise noted, answers for all measures were provided on a 5 -point Likert scale ranging from 1 (completely disagree) to 5 (completely agree). Means, standard deviations, and standardized factor loadings of measurement items are shown in Table 1.

\subsubsection{Technological insecurity}

We measured technological insecurity with a scale developed by Tarafdar, Ragu-Nathan, and Ragu-Nathan (2007), including the following items: "I feel constant threat to my job security due to new technologies"; "I have to constantly update my skills to avoid being replaced"; "I am threatened by coworkers with newer technology skills" and "I do not share my knowledge with my coworkers for fear of being replaced". Among others, Ragu-Nathan, Tu, Tarafdar, Raghu-Nathan (2008) validated that the items load on one single factor. Later, Chen (2015) validated the scale in a Chinese context concluding that this measure offers solid ground to further investigate technological stress in a global perspective. We excluded one item from the original five-item scale to shorten the survey.

\subsubsection{Organizational support for strengths use}

We measured an individuals' perception about the organizational support for strengths use with a scale developed by Keenan and Mostert (2013). To reduce the burden for the respondents, we excluded 4 items from the original eight-item scale, resulting in the following items: "My organization gives me the opportunity to do what I am good at"; "My organization allows me to use my talents"; "My organization ensures that my strengths are aligned with my job tasks"; and "My organization allows me to do my job in a manner that best suits my strong points".

\subsubsection{Friendship opportunities}

We used three items from the Friendship Opportunity scale validated by Sims et al. (1976) and later adapted and included in the Social Support Scale as part of the Work Design Questionnaire (WDQ) (Morgeson \& Humphrey, 2006; Sims et al., 1976). The questionnaire was modeled to capture work characteristics for research purposes. Specifically, survey participants were asked about their perception to which extent they think to have the opportunities to establish friendships and receive social contact with others in their workplace. The items used are as follows: "I have the opportunity to develop close friendships in my job"; "I have the chance in my job to get to know other people"; and "I have the opportunity to meet with others in my work.". 
Table 2

Exploratory factor loadings and interitem correlations of the studied latent constructs.

\begin{tabular}{|c|c|c|c|c|c|c|c|c|c|c|c|c|c|c|}
\hline & \multirow[t]{2}{*}{ Items } & \multicolumn{3}{|c|}{ Factor Loadings } & \multicolumn{10}{|c|}{ Interitem Correlations } \\
\hline & & F1 & $\mathrm{F} 2$ & F3 & 1 & 2 & 3 & 4 & 5 & 6 & 7 & 8 & 9 & 10 \\
\hline 1 & Technological insecurity I & .71 & & & & & & & & & & & & \\
\hline 2 & Technological insecurity II & .55 & & & $.41 * *$ & & & & & & & & & \\
\hline 3 & Technological insecurity III & .81 & & & $.57 * *$ & $.44 * *$ & & & & & & & & \\
\hline 4 & Technological insecurity IV & .70 & & & $.50^{* *}$ & $.35^{* *}$ & $.57^{* *}$ & & & & & & & \\
\hline 5 & Org. Strengths use support I & & .87 & & $-.12 * *$ & .02 & $-.07 * *$ & $-.06 * *$ & & & & & & \\
\hline 6 & Org. Strengths use support II & & .85 & & $-.09 * *$ & $.06^{* *}$ & $-.03 * *$ & -.02 & $.76 * *$ & & & & & \\
\hline 7 & Org. Strengths use support III & & .86 & & $-.09 * *$ & $.03^{* *}$ & $-.05^{* *}$ & $-.04 * *$ & $.73^{* *}$ & $.72^{* *}$ & & & & \\
\hline 8 & Org. Strengths use support IV & & .85 & & $-.10 * *$ & $.04 * *$ & $-.05^{* *}$ & $-.05^{* *}$ & $.74 * *$ & $.73^{* *}$ & $.74 * *$ & & & \\
\hline 9 & Friendship opportunities I & & & .57 & .01 & .01 & .01 & .02 & $.26^{* *}$ & $.28^{* *}$ & $.25^{* *}$ & $.26^{* *}$ & & \\
\hline 10 & Friendship opportunities II & & & .63 & $-.11 * *$ & $-.04 * *$ & $-.09 * *$ & $-.09 * *$ & $.24 * *$ & $.25^{* *}$ & $.22^{* *}$ & $.23^{* *}$ & $.39 * *$ & \\
\hline 11 & Friendship opportunities III & & & .82 & $-.08 * *$ & $.04 * *$ & $-.04 * *$ & $-.06 * *$ & $.26^{* *}$ & $.27^{* *}$ & $.23^{* *}$ & $.26^{* *}$ & $.48^{* *}$ & $.52 * *$ \\
\hline
\end{tabular}

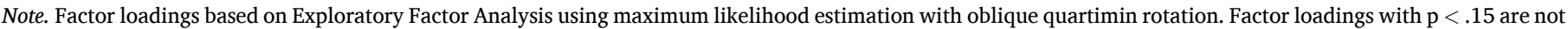
shown for clarity purposes. Interitem correlations based on unimputed data. ${ }^{*} \mathrm{p}<.05$, ** $\mathrm{p}<.01$.

\subsubsection{Construct validity and measurement model comparison}

The original latent constructs have been adapted to the German context, which requires respective construct validity testing (Hinkin, 1998). Hence, we statistically tested the validity of the three constructs with both Exploratory Factor Analysis (EFA) and Confirmatory Factor Analysis (CFA).

First, EFA has been conducted. Table 2 summarizes the EFA factor loadings and interitem correlations. Accordingly, the results show high internal consistency reliability for the three measures in this study. All measurement items consistently load on one single factor with no major intercorrelations between factors. The Eigenvalues of the three factors are higher than 1 (Kaiser criterion), and all factor loadings are surpassing .40 and thus are judged as meaningful (Ford, MacCallum, \& Tait, 1986). Further, the interitem correlations show that the items correlate more strongly with items from the same domain compared to items from another domain. The Kaiser-Meyer-Olkin measure for sampling adequacy shows an overall value of 0.83 with all items being higher than 0.73 , indicating that the items were adequate for EFA (Tabachnick, Fidell, \& Ullman, 2007). Further, every single factor shows high internal consistency reliability based on Cronbach's alpha (Price, 1997). Thus, coefficients are $0.91,0.77$, and 0.72 for the factors technological insecurity, organizational support for strengths use and friendship opportunities, respectively, with no value being below the threshold of .70 (Hinkin, 1998). Therefore, the study variables are rated as showing high internal consistency reliability for the study context at hand.

Second, the three latent constructs are validated by executing individual CFA, to test the model fit of the individual latent constructs (see Table 3). Results indicate good model fit for technological insecurity ( $\chi 2$ $=39.55$; df. $=2$; Comparative Fit index $[\mathrm{CFI}]=0.97$, Tucker-Lewis Index $[\mathrm{TLI}]=0.99$, root mean square error of approximation $[$ RMSEA $]=0.05)$ and organizational support for strengths use $(\chi 2=$ $30.34, \mathrm{df}=2, \mathrm{CFI}=1.00$, TLI $=1.00$, RMSEA $=0.04$ ). Fit indices for friendship opportunities were not able to be estimated, as the model is statistically perfectly identified ( $\mathrm{df}=0)$. Overall, the computed fit statistics indicate good fit to the data.

Last, joint CFA with items from all latent constructs was conducted for measurement model comparison (for test results see Table 4). Results showed that a three-factor model with technological insecurity, organizational support for strength use and friendship opportunities loading on three separate factors $(\chi 2=562.41$; $\mathrm{df} .=41$; CFI $=0.99$, TLI $=0.98$, RMSEA $=0.04)$ fits significantly better to the data than a twofactor model with organizational support for strengths use and friendship opportunities loading on one factor and technological insecurity on a second factor $(\Delta \chi 2=3730.91, \mathrm{df}=2, \mathrm{p}<.001, \mathrm{CFI}=0.89, \mathrm{TLI}=0.86$, RMSEA $=0.11$ ), as well as a model with all three constructs loading on one single factor $(\Delta \chi 2=12622.76, \mathrm{df}=3, \mathrm{p}<.001, \mathrm{CFI}=0.65$, TLI $=$ 0.57 , RMSEA $=0.19)$.

Overall, the combined results from EFA and CFA indicate high construct validity of the latent constructs under investigation. Based on those results, we assume that the applied transfer to the German context was appropriate. Thus, the constructs were used as described.

\subsubsection{General health}

General health was captured by using a single-item measure, generated based on the WAI (Work Ability Index) first item (i.e., current work ability compared with best) (Tuomi, Ilmarinen, Jahkola, Katajarinne, \& Tulkki, 1998). We asked participants to indicate their current (general) health when being compared to the best possible. The item used was "When indicating the best conceivable health condition with 10 points and the worst with 0 points: How would you assess your current health condition?" Answers were provided on a 11-point Likert type scale, ranging from 0 (worst possible) to 10 (best possible). Opposed to all other study variables, data for general health was used from the second study wave to reduce single source bias. The average health status was $7.84(S D=2.03)$.

We chose to assess perceived general health using self-reported measures that can provide more accurate health information compared to objectively verifiable health indicators (Burr, Kersten, Kroll, \& Hasselhorn, 2013; De Witte et al., 2016; Wurm, Tomasik \& Tesch-Roemer, 2008). For instance, objective indicators (e.g., cortisol levels) might be misleading because they are a highly isolated health measure and deviations between individuals can likely occur due to genetic differences; thus, they might not be detrimental for ones' health.

Further, we decided to use a single-item measure because when collecting a vast amount of data across several time points, it is crucial to minimize the burden on respondents which has shown to have negative

Table 3

Summary of results from individual confirmatory factor analysis (CFA) construct validation.

\begin{tabular}{|c|c|c|c|c|c|c|c|c|c|}
\hline & Latent Constructs & $N$ & $\chi^{2}$ & $d f$ & AIC & BIC & CFI & $T L I$ & RMSEA \\
\hline 1 & Technological insecurity & 8019 & $39.55^{* *}$ & 2 & 81593.59 & 81677.46 & .97 & .99 & .05 \\
\hline 2 & Org. Strength use support & 8017 & $30.34 * *$ & 2 & 69561.03 & 69644.67 & 1.00 & 1.00 & .04 \\
\hline 3 & Friendship opportunities & 8012 & 0 & 0 & 68857.32 & 68919.99 & .00 & 1.00 & 1.00 \\
\hline
\end{tabular}

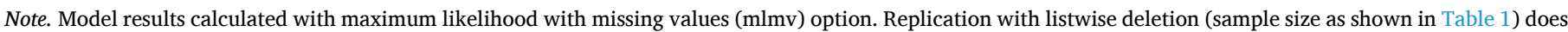

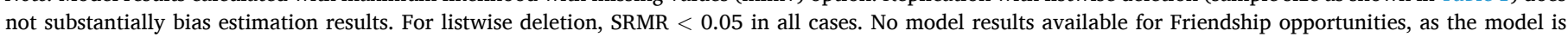

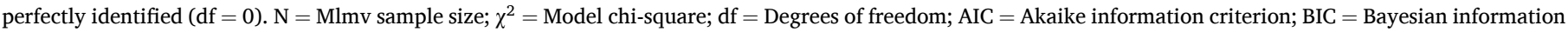
criterion; CFI = comparative fit index; TLI = tucker lewis index; RMSEA = root mean square error of approximation; *p $<.05$, ** $<$.01. 
Table 4

Summary of results from joint confirmatory factor analyses (CFA) measurement model comparison.

\begin{tabular}{|c|c|c|c|c|c|c|c|c|c|c|c|}
\hline & CFA Model & $\Delta \chi 2$ & $\Delta d f$ & $\chi^{2}$ & $d f$ & AIC & $B I C$ & CFI & $T L I$ & RMSEA & $90 \%$ CI \\
\hline 1 & One-Factor Model & $12622.76^{* *}$ & 3 & 13185.17 & 44 & 233971.35 & 234202.01 & .65 & .57 & .19 & n.a. \\
\hline 2 & Two-Factor Model & $3730.91^{* *}$ & 2 & 4293.31 & 43 & 225081.50 & 225319.14 & .89 & .86 & .11 & $.108-.114$ \\
\hline 3 & Three-Factor Model & - & - & 562.41 & 41 & 221354.59 & 221606.21 & .99 & .98 & .04 & $.037-.043$ \\
\hline
\end{tabular}

Note. $N=8019$. Models calculated using maximum likelihood with missing values (mlmv) option. $\Delta \chi^{2}=$ Model chi-square difference; $\Delta d f=D$ egrees of freedom

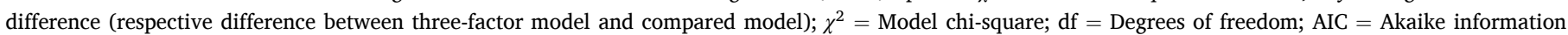

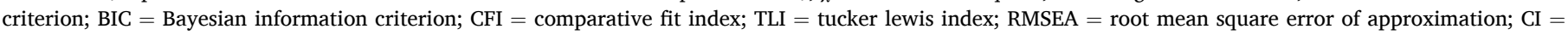
confidence interval; *p $<.05,{ }^{*} * \mathrm{p}<.01$.

effects on response rates (Crabtree, 2004; Fisher, Matthews, \& Gibbons, 2016). Alternative multiple-item measures commonly contain many items (e.g., SF-36 scale, see Ware \& Gandek, 1998; World Health Organization, 2010) that are very time-consuming to complete and thus result in higher attrition.

Further, Fisher et al. (2016) pointed out that multiple-item measures within occupational health psychology often omit construct-relevant items and maintain construct-irrelevant ones. This is particularly relevant when "the survey is administered to a wide range of different populations" (Petrescu, 2013, p. 113), as item relevance may vary. Due to the high interpretability, face validity, and general lack of repetition of single-item measures (Metz et al., 2007), "they allow testing more holistic or thorough models of relations among constructs" (Fisher et al., 2016, p. 3). This led to the recommendation to assess health using more general single-item measures (Fisher et al., 2016).

Accordingly, in the field of "occupational health psychology [..] [,] single-item measures have attained a degree of respectability [...] [especially when assessing] overall self-rated health" (Fisher, Matthews, \& Gibbons, 2016, p. 4). Ensuring high validity and not overloading respondents who might eventually drop out, single-item measures are commonly used to assess general health in population-representative surveys (Burr et al., 2013). Hence, we regard the use of our selected measure as appropriate for this study.

\subsubsection{Control variables}

We included disability status ( $0=$ no; $1=$ yes $)$ as control variable, because having a disability, by definition directly affects the current health assessment compared to one's best conceivable health condition. Therefore, not incorporating disability status might strongly bias the observed effects on a perceived health outcome (McDowell, 2006; Røysamb, Tambs, Reichborn-Kjennerud, Neale, \& Harris, 2003). In similar vein, we also account for a sporty or healthy lifestyle by using the average hours of workouts per week as a proxy. Physical activity has shown to be a strong predictor of physical and mental health (Bize, Johnson, \& Plotnikoff, 2007; Haskell, Lee, Pate, Powel, \& Blair, 2007). Furthermore, the official working hours per week (by contract, in hours) were measured as a proxy of the degree of how much people interact within their work environment. This control captures potential work overload issues and the relevance (and impact) of work (demands) on employees' health ratings (McDowell, 2006; Sluiter, De Croon, Meijman, \& Frings-Dresen, 2003). Being exposed to demanding work conditions for a prolonged period of time, employees are more likely to suffer from negative health effects caused by these conditions. Unobservable work-related factors will influence general assessments about life more when spending more time at work.

In addition, based on the sample structure, having participants from many different companies and occupational backgrounds, which is known to have an effect in study designs due to self-selection bias (Antonakis, Bendahan, Jacquart, \& Lalive, 2010), we also account for those effects. In doing so, we incorporated the operating sector (branch) of the company the participants work for (i.e. 22 categories that cluster the German industry sectors from "Banking, insurance, real estate" to "Government, administration, public services") and the type of occupation the participants perform in their respective company (i.e. 14 categories ranging from "Occupations in business management" to "Occupations in cleaning services"; Federal Agency of Employment, 2011). as control variables. We also control for the respective job position of the participants (i.e. 11 categories ranging from different types of self-employment (freelancers, self-employed, etc.), lower-tier to higher-tier employees and civil servants, and several categories of blue-collar workers). Additionally, gender $(0=$ female; $1=$ male), age (in years), organizational tenure (in years) and educational level (i.e. six categories ranging from "still in education or training" to "university degree") are incorporated.

\subsection{Analysis}

To analyze the superior effect of a three-way interaction model, we conducted hierarchical moderated multiple regressions (HMMR) with a time-lagged dependent variable using Stata 15 (StataCorp., 2017). For each latent independent construct in the analysis, a single-indicator factor score was obtained after confirmatory factor analysis within every single imputed dataset. Furthermore, we grand-mean centered all continuous control variables after imputation. Categorical controls were included as dummies. Interaction terms to test for moderating effects were computed by using factor variables of the respective factor scores involved within regression. All models with full data were estimated by using Stata's mi estimate command. Hence, Model 1 contains solely the control variables. In model 2 , the main effects of the three independent variables were added to test Hypothesis 1. Following the hierarchical structure, model 3 additionally included the moderation term of technological insecurity and organizational strengths use support to test Hypothesis 2. To test Hypothesis 3, model 4 included the interaction of technological insecurity and friendship opportunities. Model 5 incorporated the interaction of organizational strength use support and friendship opportunities. Finally, model 6 incorporated the three-way interaction term to test Hypothesis 4. With multiply imputed data it is not possible to perform incremental $F$ tests of the $\mathrm{R}^{2}$ changes to test nested models against each other. Therefore, in order to compare the different (nested) models several joint tests by using Stata's mi test command were conducted - following the null hypothesis that coefficients on several variables are simultaneously equal to zero (StataCorp., 2017). Finally, we performed a simple slope analysis of the interaction effects one standard deviation above and below the mean of the interacting variables ${ }^{2}$ to illustrate the interaction effects (Aiken \& West, 1991). To further illustrate the nature of the three-way interaction we also followed the approach recommended by Dawson and Richter (2006) for comparing the corresponding slopes amongst each other. ${ }^{3}$

\footnotetext{
${ }^{2}$ Standard Deviations of extracted factor scores above and below zero mean: Technological insecurity (0.98), organizational support for strength use (0.94) and friendship opportunities (0.94).

${ }^{3}$ No observations with 'impossible' values or 'response patterns' were identified in the survey. Also, no responses were able to be classified as outliers due to 'extreme' values. The latter is mainly because of the use of Likert Scales for the measurement of the main study variables. Yet, applying the common SDmethod (3-SD \pm variable mean) for all continuous and Likert-scale variables prior to imputation as a robustness check did not lead to substantially different estimation results. Therefore, we assume that our analysis is not substantially biased due to outliers.
} 
Table 5

Means, standard deviations and correlations between the study variables.

\begin{tabular}{|c|c|c|c|c|c|c|c|c|c|c|c|c|c|c|c|c|}
\hline & Variables & M & SD & 1 & 2 & 3 & 4 & 5 & 6 & 7 & 8 & 9 & 10 & 11 & 12 & 113 \\
\hline 1 & Gender $(0=$ female, $1=$ male $)$ & .51 & .50 & & & & & & & & & & & & & \\
\hline 2 & Age (in years) & 44.3 & 11.4 & $.12^{* *}$ & & & & & & & & & & & & \\
\hline 3 & Disability status $(0=$ no, $1=$ yes $)$ & .12 & .32 & $.04 * *$ & $.16^{* *}$ & & & & & & & & & & & \\
\hline 4 & Educational level a & 4.75 & 1.00 & $-.05^{* *}$ & $-.10 * *$ & $-.11 * *$ & & & & & & & & & & \\
\hline 5 & Official working hours per week & 35.1 & 8.99 & $.33^{* *}$ & $-.09 * *$ & $-.05^{* *}$ & $.11^{* *}$ & & & & & & & & & \\
\hline 6 & Organizational tenure & 11.4 & 10.3 & $.15^{* *}$ & $-.46^{* *}$ & $.10^{* *}$ & $-.06 * *$ & $.10 * *$ & & & & & & & & \\
\hline 7 & Sport hours per week ${ }^{b}$ & - & - & - & - & - & - & - & - & & & & & & & \\
\hline 8 & Job position ${ }^{b}$ & - & - & - & - & - & - & - & - & - & & & & & & \\
\hline 9 & Occupation segment ${ }^{\mathrm{b}}$ & - & - & - & - & - & - & - & - & - & - & & & & & \\
\hline 10 & Companies' operating sector ${ }^{b}$ & - & - & - & - & - & - & - & - & - & - & - & & & & \\
\hline 11 & Technological insecurity $^{c}$ & 1.80 & 0.98 & $.07^{* *}$ & $-.14 * *$ & $.03^{* * *}$ & -.00 & $.07^{* *}$ & $-.03 *$ & - & - & - & - & & & \\
\hline 12 & Org. Strengths use support ${ }^{c}$ & 3.62 & 0.94 & $.06^{* *}$ & $.05^{* *}$ & $-.06^{* *}$ & $.09^{* *}$ & .02 & -.01 & - & - & - & - & $-.10 * *$ & & \\
\hline 13 & Friendship opportunities ${ }^{c}$ & 3.51 & 0.94 & $.06^{* *}$ & $-.03 *$ & $-.06^{* *}$ & $.11^{* *}$ & $.07 * *$ & .01 & - & - & - & - & $-.11^{* *}$ & $-.48 * *$ & \\
\hline 14 & General health (T2) & 7.84 & 2.03 & .01 & $-.08 * *$ & $-.26^{* *}$ & $.13^{* *}$ & $.04 *$ & $-.03 *$ & - & - & - & - & $-.10 * *$ & $-.20 * *$ & $-.16^{* *}$ \\
\hline
\end{tabular}

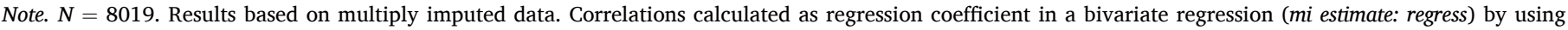
standardized variable forms for both independent and dependent variable, respectively.

* $p<.05, * * \mathrm{p}<.01$.

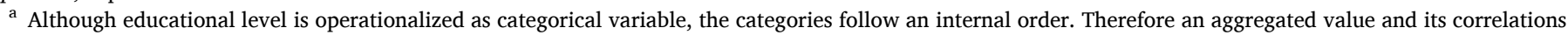
offer some valuable information and thus, is shown.

b Correlations with aggregated categorical variables (with no internal order) are not interpretable and therefore not executed.

${ }^{c}$ For descriptive purposes, the means and standard deviations derived from an aggregated construct (index) consisting of all respective indicator variables (without centering).

\section{Results}

Table 5 shows the means, standard deviations and the correlations among the study variables. Herein, correlation coefficients were all in the expected direction. Additionally, results of the conducted hierarchical regression analysis are reported in Table 6. Supporting Hypothesis 1, Model 2 shows a significant direct and negative effect of technological insecurity assessed at time 1 on general health assessed at time $2(B=-.27, p<.001 ; F=81.47, d f=3, p<.01)$.

In support for Hypothesis 2, Model 3 shows the results of general health at time 2 regressed on the interaction term for technological insecurity and organizational support for strength use in time 1 , thus indicating a positive relation $(B=0.12, p<.01 ; F=9.94, d f=1, p<.01$; cf. Fig. 2). Simple slope tests indicated significant slopes for both employees with low support for strength use $(B=-0.38, S E=0.05, p<$ $.01)$ and the respective high-level condition $(B=-0.17, S E=0.05, p<$

Table 6

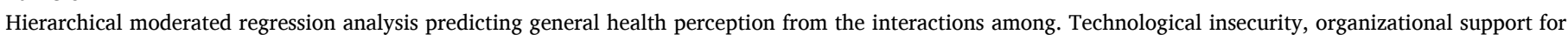
strength use, and friendship opportunities.

\begin{tabular}{|c|c|c|c|c|c|c|c|c|c|c|c|c|}
\hline \multirow[t]{3}{*}{ Variables (T1) } & \multicolumn{12}{|c|}{ General Health (T2) } \\
\hline & \multicolumn{2}{|l|}{1} & \multicolumn{2}{|l|}{2} & \multicolumn{2}{|l|}{3} & \multicolumn{2}{|l|}{4} & \multicolumn{2}{|l|}{5} & \multicolumn{2}{|l|}{6} \\
\hline & Estimate & $S E$ & Estimate & $S E$ & Estimate & $S E$ & Estimate & $S E$ & Estimate & $S E$ & Estimate & $S E$ \\
\hline Constant & $7.75^{* *}$ & .95 & $7.53^{* *}$ & .95 & $7.58^{* *}$ & .96 & $7.58^{* *}$ & .95 & $7.52^{* *}$ & .95 & $7.60^{* * *}$ & .96 \\
\hline Gender $(0=$ female, $1=$ male $)$ & .06 & .05 & .05 & .05 & .05 & .05 & .05 & .05 & .05 & .05 & .06 & .05 \\
\hline Age (in years) & -.00 & .00 & $-.01 * *$ & .00 & $-.01 * *$ & .00 & $-.01 * *$ & .00 & $-.01 * *$ & .00 & $-.01 * *$ & .00 \\
\hline Disability status $(0=n o, 1=y e s)$ & $-1.41^{* *}$ & .08 & $-1.33^{* *}$ & .08 & $-1.33^{* *}$ & .08 & $-1.33^{* *}$ & .08 & $-1.33^{* *}$ & .08 & $-1.33^{* *}$ & .08 \\
\hline Working hours per week & .00 & .00 & .00 & .00 & .00 & .00 & .00 & .00 & .00 & .00 & .00 & .00 \\
\hline Organizational tenure & .00 & .00 & .00 & .00 & .00 & .00 & .00 & .00 & .00 & .00 & .00 & .00 \\
\hline Educational level & c & c & c & c & c & c & $\mathrm{c}$ & c & c & c & c & c \\
\hline Sport hours per week & c & c & $\mathrm{c}$ & $\mathrm{c}$ & $\mathrm{c}$ & c & $\mathrm{c}$ & $\mathrm{c}$ & c & $\mathrm{c}$ & $\mathrm{c}$ & $\mathrm{c}$ \\
\hline Job position & $\mathrm{c}$ & c & $\mathrm{c}$ & $\mathrm{c}$ & $\mathrm{c}$ & c & $\mathrm{c}$ & $\mathrm{c}$ & $\mathrm{c}$ & $\mathrm{c}$ & $\mathrm{c}$ & $\mathrm{c}$ \\
\hline Occupational segment & $\mathrm{c}$ & c & $\mathrm{c}$ & $\mathrm{c}$ & $\mathrm{c}$ & c & $\mathrm{c}$ & $\mathrm{c}$ & $\mathrm{c}$ & $\mathrm{c}$ & $\mathrm{c}$ & $\mathrm{c}$ \\
\hline Companies' operating sector & $\mathrm{c}$ & c & c & $\mathrm{c}$ & c & $\mathrm{c}$ & $\mathrm{c}$ & $\mathrm{c}$ & c & $\mathrm{c}$ & $\mathrm{c}$ & c \\
\hline Technological insecurity (X) & & & $-.27 * *$ & .04 & $-.27 * *$ & .04 & $-.27^{* *}$ & .04 & $-.27 * *$ & .04 & $-.31 * *$ & .04 \\
\hline Org. Strength use support (M1) & & & $.30 * *$ & .03 & $.30 * *$ & .03 & $.30 * *$ & .03 & $.31^{* *}$ & .03 & $.31^{* *}$ & .03 \\
\hline Friendship opportunities (M2) & & & $.15^{* *}$ & .05 & $.15^{* *}$ & .05 & $.16^{* *}$ & .05 & $.16^{* *}$ & .04 & $.16^{* *}$ & .05 \\
\hline $\mathrm{X} \times \mathrm{M} 1$ & & & & & $.12^{* *}$ & .04 & & & & & $.11^{*}$ & .05 \\
\hline $\mathrm{X} \times \mathrm{M} 2$ & & & & & & & $.18^{* *}$ & .05 & & & $.13^{*}$ & .06 \\
\hline M1 $\times$ M2 & & & & & & & & & .05 & .04 & .07 & .04 \\
\hline $\mathrm{X} \times \mathrm{M} 1 \times \mathrm{M} 2$ & & & & & & & & & & & $.14^{* *}$ & .05 \\
\hline F-value ${ }^{a}$ & $11.84 * *$ & & $81.47^{* *}$ & & $9.94^{* * *}$ & & $10.73^{* *}$ & & 1.45 & & $6.46^{* * \mathrm{~b}}$ & \\
\hline $\mathrm{R}^{2}$ (Fisher-z) & .125 & & .164 & & .166 & & .166 & & .164 & & .168 & \\
\hline
\end{tabular}

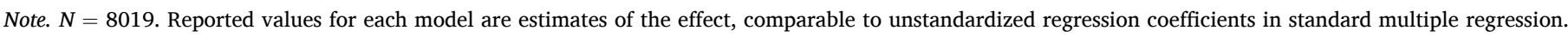

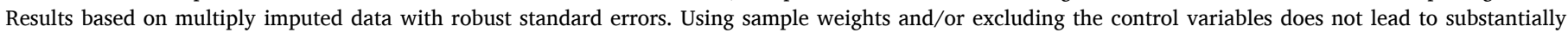
different results.

$* \mathrm{p}<.05, * * \mathrm{p}<.01$.

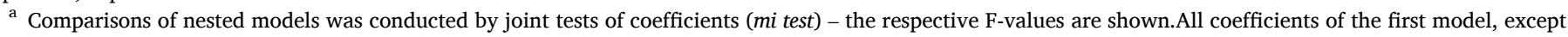

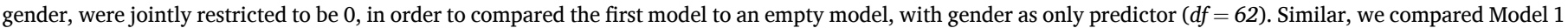
with Model 2: $d f=3$, Model 2 with Model 3: $d f=1$, Model 2 with Model 4: $d f=1$, Model 2 with Model 5: $d f=1$, and Model 2 with Model 6: $d f=4$.

b Secondly, Model 6 was compared with Model $3(F=4.74, p<0.01, d f=3)$, Model $4(F=4.65, p<0.01, d f=3)$, and Model $5(F=8.27, p<0.01, d f=3)$.

c Categorical variables were included as dummies within regression. For reasons of clarity, results for those categorical controls are excluded in results table. 


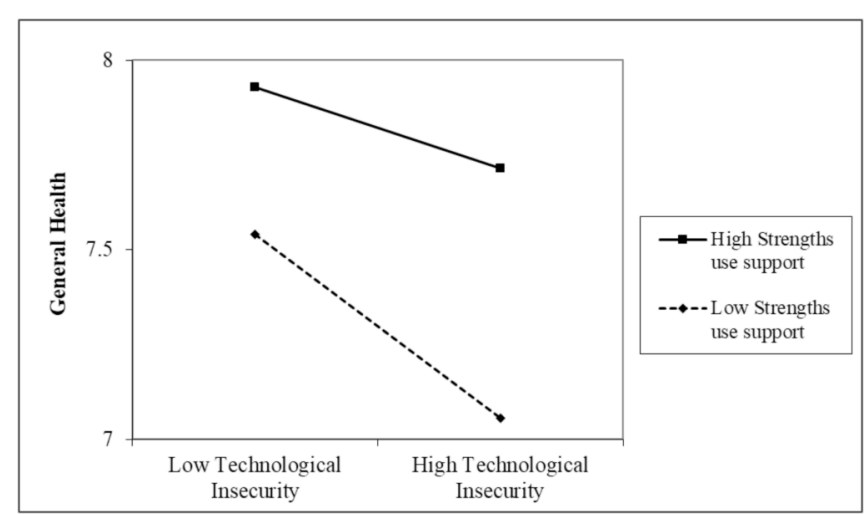

Fig. 2. Plot of the two-way interaction effect of technological insecurity and organizational support for strengths use on general health.

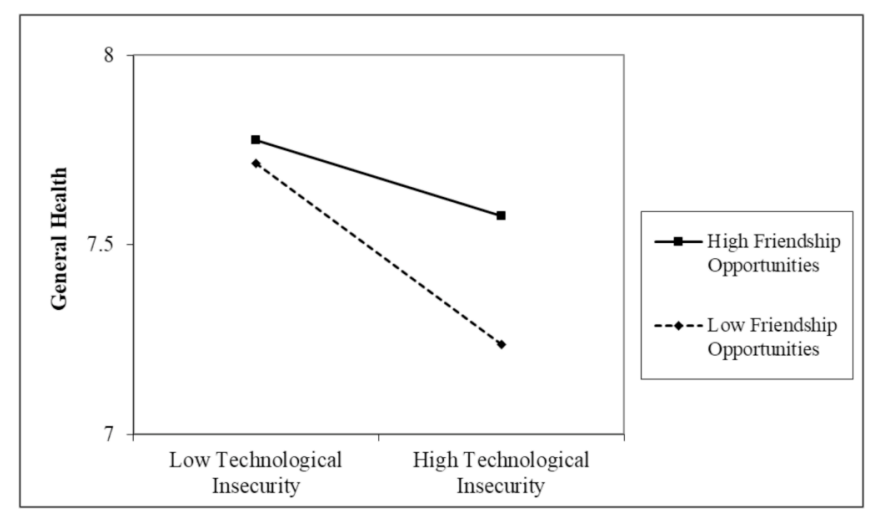

Fig. 3. Plot of the two-way interaction effect of technological insecurity and friendship opportunities on general health.

.01). This supports our hypothesis that higher levels of strengths use support buffer the negative effect of technological insecurity on general health over and above all controls.

In a similar vein, Model 4 shows the interaction effect of technological insecurity and friendship opportunities at time 1 to be positively related to general health at time $2(B=0.18, p<.01 ; F=9.94, d f=1, p$ $<.01$; cf. Fig. 3). Simple slope tests indicate that the relationship is significant for both low levels $(B=-0.38, S E=0.05, p<.01)$ and high levels $(B=-0.16, S E=0.05, p<.01)$ of friendship opportunities in the workplace, indicating that the negative relationship of technological insecurity on general health is stable under low and high conditions of friendship opportunities, but will be buffered more when friendship opportunities are high. Therefore, Hypothesis 3 found support.

Furthermore, Model 5 shows that the combination of both job resources at time 1 , strengths use support and friendship opportunities per se, in absence of the stressful job condition technological insecurity, does not have a buffering effect on general health at time 2 beyond the simple direct effects caused by the individual resources $(B=0.05, p>$ $.05 ; F=1.45, d f=1, p>.05$; cf. Fig. 4 ).

To test Hypothesis 4, model 6 shows a significant three-way interaction in the expected direction $(B=0.14, p<.01 ; F=5.42, d f=4, p<$ .01 ; cf. Fig. 5). Simple slopes indicate that solely the slope for high organizational support for strength use (I) and high friendship opportunities (II) was not significant (I $\uparrow \mathrm{II} \uparrow: B=-.06, S E=0.06, p>.05$ ), while all other slopes are significant (I $\downarrow$ II $\downarrow$ : $B=-0.42, S E=0.06, p<$ $.01 ; \mathrm{I} \uparrow \mathrm{II} \downarrow: B=-0.37, S E=0.09, p<.01 ; \mathrm{I} \downarrow \mathrm{II} \uparrow: B=-0.40, S E=0.10, p<$ .01 , respectively). This means that technological insecurity at time 1 is not negatively related to general health at time 2 under the condition of high organizational support for strength use and high friendship opportunities in the workplace - supporting the thesis of a strong buffering effect, occurring as a total ruling out effect, of organizational job resources when establishing both in high conditions. Additionally, by comparing the three-way interaction slopes among each other (Dawson \& Richter, 2006), results show the slope with high organizational strength use support and high friendship opportunities to be significantly different from all other slopes ( $p<.01$ w.r.t. all other slopes). Also, all other slopes do not differ significantly from each other $(p>.05$ in all other cases). This result is an additional indication of the superior amelioration effect of the resources organizational support for strength use and friendship opportunities on the technological insecurity - general health link, when being present in high levels.

\section{Discussion}

The results from the time-lagged regression analysis indicate that perceptions of technological insecurity influences employees' perceived health over time. Specifically, we observe that the perceptions of technological insecurity negatively affect employees' health perception nine months later. Furthermore, we find this relationship to become weaker when employees' perceive to be supported by the organization in using their individual strengths in the workplace and/or their work enables them to build friendships. When employees' perceive those two aspects

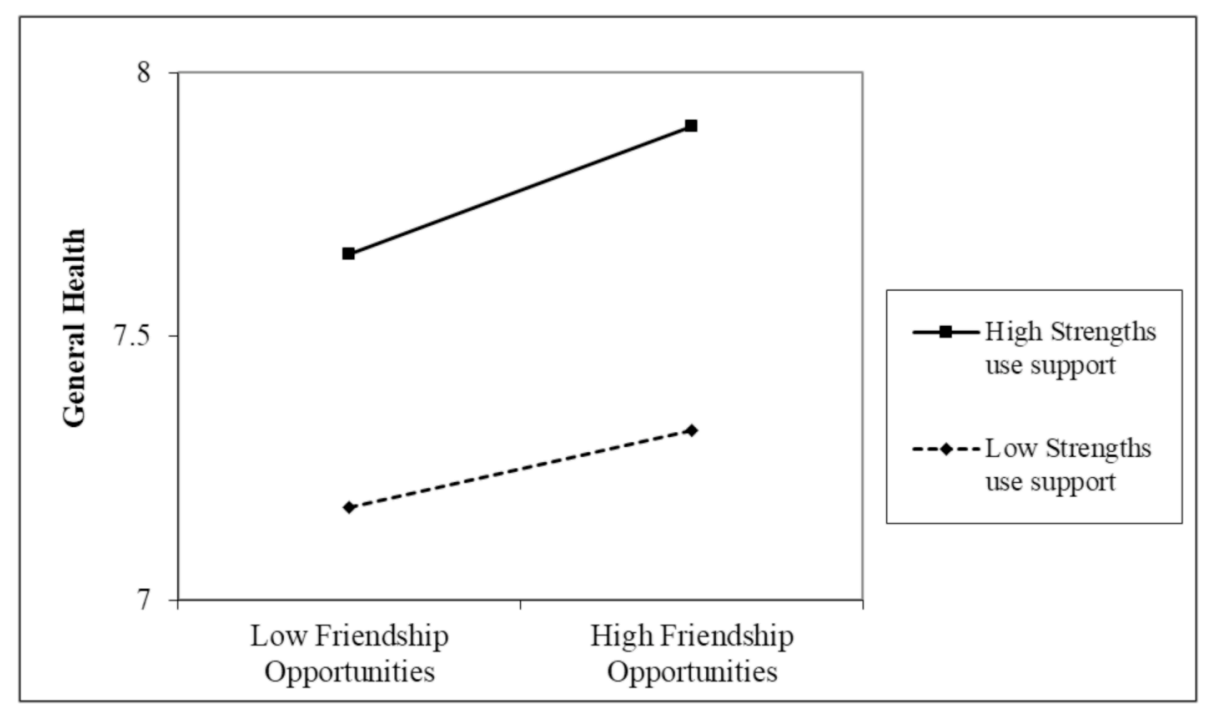

Fig. 4. Plot of the two-way interaction effect of organizational support for strength use and friendship opportunities on general health. 


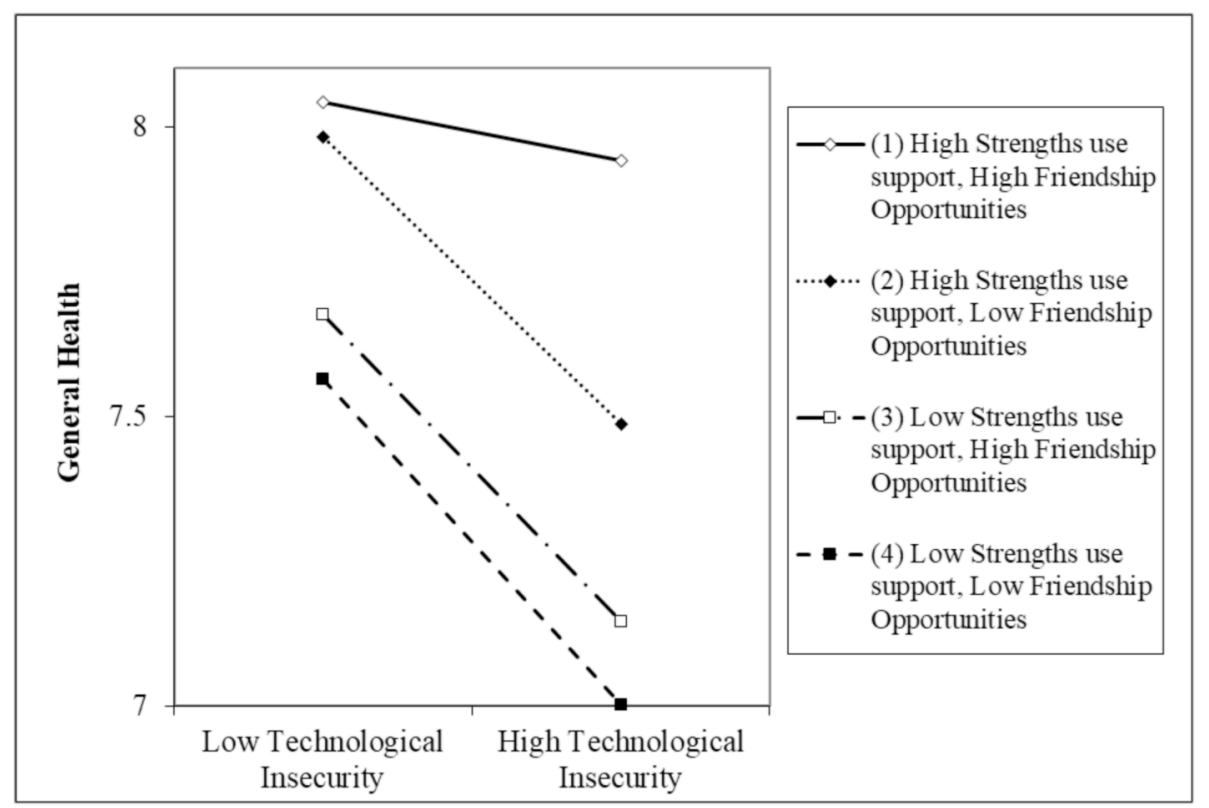

Fig. 5. Plot of the three-way interaction effect of technological insecurity, organizational support for strengths use, and friendship opportunities on general health.

to be highly present, we no longer find a time-lagged effect of technological insecurity on ones' general health perception. The examined relationships are derived and in line with COR theory, one of the dominant theories in psychological stress literature to theorize individual stress.

More theoretically, the study shows that the impact of technostress creators (e.g. technological insecurity) on individuals is context specific. Even more, derived from COR theory it is the first study to show that non-technology-related organizational resources (organizational support for strength use $\times$ friendship opportunities) play a crucial role in determining the extent to which individuals are affected by ICTs. Thus, adapting organizational resources may act as a buffering strategy to deal with rising technological insecurity concerns in the digital era. Although there is research about the negative effects and consequences of technostress (Ayyagari et al., 2011; Ragu-Nathan et al., 2008; Srivastava et al., 2015), previous research still lacks on strategies on how to effectively and adequately cope with those new forms of stress from a non-technology-related organizational environment perspective. Hence, the findings at hand are particularly important because they provide initial support for the high value of this research direction.

Moreover, our results indicate that applying established theories from other disciplines in the context of IS research is valuable. More specifically, relying on COR theory (Hobfoll, 2001, 2011) from psychological stress literature to analyze the effects of technostress constructs on individuals allows to uncover more complex relationships. Doing so, the study provides initial support for the emphasis of Tarafdar et al. (2017), who claimed the need for IS literature to combine research of technostress (constructs) with non-IS research on (psychological) stress and organizational behavior. This enables to gain valuable theoretical insights on how to cope with uprising stressor(s) in times of inevitable technological change.

By using structural weights, we draw on representative data for approximately 33.3 million employees in Germany, being of full age and having access to internet-enabled ICTs. This strengthens both the internal and external validity of the results.

\subsection{Limitations and future research}

Despite methodological strengths such as high statistical power, representative data, time-lagged data and the related absence of singlesource bias (Podsakoff, MacKenzie, Lee, \& Podsakoff, 2003), this study still has certain methodological limitations. First, the study is cross-sectional in nature, which leads to associated limitations with regard to causality. For example, low perceptions of one's general health might be the reason rather than the consequence of high technological insecurity. Although generating the amount and quality of data at hand is time and cost-intensive, we encourage future studies to focus on longitudinal study designs to enable causal interpretations.

In addition, our study provides findings based on a study sample representative for respective employees in Germany. This makes the generalizability to employees in other countries questionable. Replication studies with data from other countries are thus encouraged to validate the study results.

Third, study data is generated via surveys conducted by a market research institute. As common practice, by using participants being preregistered in the institutes' survey panels, we cannot rule out selfselection bias of the people tending to participate in those surveys regularly. The development of data generation procedures, able to minimize self-selection bias, are encouraged.

Fourth, although the use of self-reported single-item measures of perceived health are regarded as adequate for the study at hand, we acknowledge that the use of other measures might lead to slightly different results. Thereof, with rising statistical computation possibilities we also encourage to examine relationships jointly from different health perspectives, i.e. by using both subjective and objective measures (e.g. cortisol levels) or the use of more holistic measures of health, i.e. full workability index (Tuomi et al., 1998).

At last, by providing initial support for both the relevance of theories outside the IS research stream and the context-specificity of technostress effects (i.e. technological insecurity), we strongly encourage future scholars to further integrate existing theories in IS literature.

\subsection{Practical implications}

By showing strong indication for an accumulative buffering effect of organizational resources, the study at hand provides a clear toolbox for reducing the impact of highly stressful conditions on employees' health perceptions in times of technological change. Our findings suggest that organizational support for strength use and friendship opportunities are of high value for employees to cope with technological insecurity perceptions.

According to those findings, strengths use support can be established 
by providing training for employees and supervisors that focus on the superior positive effects to use individual strengths at work rather than compensating deficits. Additionally, organizations may introduce platforms for employees to mention their personal interests and strengths. This may facilitate their integration in future decisions by the supervisor. With regard to friendship opportunities, organizations may increase the possibilities for employees to participate in activities with their colleagues by offering teambuilding events or organizational wide festivities. Also, it may be advisable to increase work and break flexibility. This may enhance the opportunities for employees to interact with colleagues they want to while not being restricted to formal work conditions (e.g. flexible working times; flexible break sequences). Further, sophisticated public socialization zones, such as cafés, in which employees may have private conversations amongst each other during breaks may increase the likelihood to build up social ties. Doing so may facilitate friendship opportunities in the workplace.

To bring both components together, possibilities in which employees can communicate their personal interests and strengths with their direct colleagues may be valuable. Colleagues can profit from this knowledge when being confronted with difficult tasks. In the future they know whom to ask for support. On the one hand this may lead to increased feelings of individual value and socialization of the supporter due to its requested personal strengths. On the other hand it may cause decreased stress levels for the colleagues who received the requested support. Overall, our results suggest that adapting the organizational environment may reduce the impact of ICT-related psychological stress, and thus, contribute to employees' health in times of enhanced digitization.

\section{Declaration of competing interest}

No competing financial interests exist.

\section{CRediT authorship contribution statement}

Tim M. Goetz: Conceptualization, Methodology, Software, Validation, Formal analysis, Investigation, Data curation, Writing - original draft, Writing - review \& editing, Visualization, Supervision, Project administration. Stephan A. Boehm: Conceptualization, Investigation, Resources, Writing - review \& editing, Supervision, Project administration, Funding acquisition.

\section{References}

Abildgaard, J. S., Nielsen, K., \& Sverke, M. (2018). Can job insecurity be managed? Evaluating an organizational-level intervention addressing the negative effects of restructuring. Work \& Stress, 32(2), 105-123.

Aiken, L. S., \& West, S. G. (1991). Multiple regression: Testing and interpreting interactions. London, England: Sage.

Antonakis, J., Bendahan, S., Jacquart, P., \& Lalive, R. (2010). On making causal claims: A review and recommendations. The Leadership Quarterly, 21(6), 1086-1120.

Asendorpf, J. B., Van De Schoot, R., Denissen, J. J., \& Hutteman, R. (2014). Reducing bias due to systematic attrition in longitudinal studies: The benefits of multiple imputation. International Journal of Behavioral Development, 38(5), 453-460.

Ayyagari, R., Grover, V., \& Purvis, R. (2011). Technostress: Technological antecedents and implications. MIS Quarterly, 35(4), 831-858.

Barney, J. B. (1985). Dimensions of informal social network structure: Toward a contingency theory of informal relations in organizations. Social Networks, 7(1), $1-46$.

Berman, E. M., West, J. P., \& Richter, M. N. (2002). Workplace relations: Friendship patterns and consequences (according to managers). Public Administration Review, 62 (2), 217-230

Biswas-Diener, R., Kashdan, T. B., \& Minhas, G. (2011). A dynamic approach to psychological strength development and intervention. The Journal of Positive Psychology, 6(2), 106-118.

Bize, R., Johnson, J. A., \& Plotnikoff, R. C. (2007). Physical activity level and healthrelated quality of life in the general adult population: A systematic review. Preventive Medicine, 45(6), 401-415.

Brod, C. (1984). Technostress: The human cost of the computer revolution. Reading, MA: Addison-Wesley Publishing Company.

Buote, V. M., Pancer, S. M., Pratt, M. W., Adams, G., Birnie-Lefcovitch, S., Polivy, J., et al. (2007). The importance of friends: Friendship and adjustment among 1st-year university students. Journal of Adolescent Research, 22(6), 665-689.
Burr, H., Kersten, N., Kroll, L., \& Hasselhorn, H. M. (2013). Self-rated general health by occupation and age in the working population in Germany. Bundesgesundheitsblatt, Gesundheitsforschung, Gesundheitsschutz, 56(3), 349-358.

Buckingham, M. (2005). What great managers do. Harvard Business Review, 83, 70-79. Businesswire. (2017). New technologies will drive ICT spending back to double the rate of GDP growth, according to IDC accessed on 05/10/2019 https://www.businesswire.co $\mathrm{m} /$ news/home/20171018005296/en/New-Technologies-Drive-ICT-Spending-Do uble-Rate.

Chen, L. (2015). Validating the technostress instrument using a sample of Chinese knowledge workers. Journal of International Technology and Information Management, 24(1), 65-82.

Chiaburu, D. S., \& Harrison, D. A. (2008). Do peers make the place? Conceptual synthesis and meta-analysis of coworker effects on perceptions, attitudes, OCBs, and performance. Journal of Applied Psychology, 93(5), 1082-1103.

Federal Agency of Employment. (2011). Classification of occupations 2010. Nuremberg: Federal Agency of Employment.

Colbert, A. E., Brono, J. E., \& Purvanova, R. K. (2016). Flourishing via workplace relationships: Moving beyond instrumental support. Academy of Management Journal, 59(4), 1199-1223.

Crabtree, S. (2004). Getting personal in the workplace: Are negative relationship squelching productivity in your company? Gallup Management Journal, 10(1), 208.

D'Arcy, J., Herath, T., \& Shoss, M. K. (2014). Understanding employee responses to stressful information security requirements: A coping perspective. Journal of Management Information Systems, 31(2), 285-318.

Dawson, J. F., \& Richter, A. W. (2006). Probing three-way interactions in moderated multiple regression: development and application of a slope difference test. Journal of applied psychology, 91(4), 917.

Day, A., Scott, N., \& Kelloway, E. K. (2010). Information and communication technology: Implications for job stress and employee well-being. In P. L. Perrewé, \& C. Ganster (Eds.), New developments in theoretical and conceptual approaches to job stress. (Research in occupational stress and well-being, 8 (pp. 317-350). Emerald Group Publishing Limited.

De Jong, T., Wiezer, N., de Weerd, M., Nielsen, K., Mattila-Holappa, P., \& Mockałło, Z. (2016). The impact of restructuring on employee well-being: A systematic review of longitudinal studies. Work \& Stress, 30(1), 91-114.

De Witte, H., Pienaar, J., \& De Cuyper, N. (2016). Review of 30 Years of longitudinal studies on the association between job insecurity and health and well-being: Is there causal evidence? Australian Psychologist, 51(1), 18-31.

Dollard, M. F., \& Bakker, A. B. (2010). Psychosocial safety climate as a precursor to conducive work environments, psychological health problems, and employee engagement. Journal of Occupational and Organizational Psychology, 83(3), 579-599.

Enders, C. K. (2010). Applied missing data analysis. New York, London: The Guilford Press.

European Agency for Safety and Health at Work (EU-OSHA). (2018). Foresight on new and emerging occupational safety and health risks associated with digitalisation 2025: Final report. https://osha.europa.eu/en/tools-and-publications/publications /foresight-new-and-emerging-occupational-safety-and-health-risks/view.

Fisher, G. G., Matthews, R. A., \& Gibbons, A. M. (2016). Developing and investigating the use of single-item measures in organizational research. Journal of Occupational Health Psychology, 21(1), 3-23.

Foote, N. N. (1985). Love. Psychiatry, 16, 245-251.

Ford, J. K., MacCallum, R. C., \& Tait, M. (1986). The application of exploratory factor analysis in applied psychology: A critical review and analysis. Personnel Psychology, 39(2), 291-314.

Forest, J., Mageau, G. A., Crevier-Braud, L., Bergeron, E., Dubreuil, P., \& Lavgine, G. L. (2012). Harmonious passion as an explanation of the relation between signature strengths' use and well-being at work: Test of an intervention program. Human Relations, 65(9), 1233-1252.

Frey, C. B., \& Osborne, M. A. (2017). The future of employment: How susceptible are jobs to computerisation? Technological Forecasting and Social Change, 114, 254-280.

Frey, C. B., \& Osborne, M. A. (2018, April 13). Automation and the future of work understanding the numbers accessed on 04/20/2019 https://www.oxfordmartin.ox. ac.uk/opinion/view/404.

Fuglseth, A. M., \& Søreb $\varnothing, \varnothing$. (2014). The effects of technostress within the context of employee use of ICT. Computers in Human Behavior, 40, 161-170.

Gagné, M., \& Deci, E. L. (2005). Self-determination theory and work motivation. Journal of Organizational Behavior, 26(4), 331-362.

Galluch, P. S., Grover, V., \& Thatcher, J. B. (2015). Interrupting the workplace: Examining stressors in an information technology context. Journal of the Association for Information Systems, 16(1), 2.

Gekara, V. O., \& Thanh Nguyen, V. X. (2018). New technologies and the transformation of work and skills: A study of computerisation and automation of Australian container terminals. New Technology, Work and Employment, 33(3), 219-233.

Govindji, R., \& Linley, P. A. (2007). Strengths use, self-concordance and well-being: Implications for strengths coaching and coaching psychologists. International Coaching Psychology Review, 2(2), 143-153.

Grant, A. M. (2008). Does intrinsic motivation fuel the prosocial fire? Motivational synergy in predicting persistence, performance, and productivity. Journal of Applied Psychology, 93(1), 48-58.

Halbesleben, J. R. B., Neveu, J.-P., Paustian-Underdahl, S. C., \& Westman, M. (2014). Getting to the "COR": Understanding the role of resources in conservation of resources theory. Journal of Management, 40(5), 1334-1364.

Hartup, W. W., \& Stevens, N. (1997). Friendships and adaptation in the life course. Psychological Bulletin, 121(3), 355-370.

Haskell, W. L., Lee, I.-M., Pate, R. R., Powell, K. E., Blair, S. N., Franklin, B. A., et al. (2007). Physical activity and public health: Updated recommendation for adults 
from the American college of sports medicine and the American heart association. Circulation, 116(9), 1081-1093.

Hellgren, J., \& Sverke, M. (2003). Does job insecurity lead to impaired well-being or vice versa? Estimation of cross-lagged effects using latent variable modelling. Journal of Organizational Behavior, 24(2), 215-236.

Hinkin, T. R. (1998). A brief tutorial on the development of measures for use in survey questionnaires. Organizational Research Methods, 1(1), 104-121.

von Hippel, P. T. (2013). Should a normal imputation model Be modified to impute skewed variables? Sociological Methods \& Research, 42(1), 105-138.

Hobfoll, S. E. (1989). Conservation of resources. A new attempt at conceptualizing stress American Psychologist, 44(3), 513-524.

Hobfoll, S. E. (2001). The influence of culture, community, and the nested-self in the stress process: Advancing conservation of resources theory. Applied Psychology: International Review, 50(3), 337-421.

Hobfoll, S. E. (2002). Social and psychological resources and adaption. Review of General Psychology, 6(4), 307-324.

Hobfoll, S. E. (2011). Conservation of resource caravans and engaged settings. Journal of Occupational and Organizational Psychology, 84(1), 116-122.

Hobfoll, S. E., Freedy, J. R., Green, B. L., \& Solomon, S. D. (1996). Coping in reaction to extreme stress: The roles of resource loss and resource availability. In M. Zeidner, \& N. S. Endler (Eds.), Handbook of coping: Theory, research, applications (322-349). John Wiley \& Sons.

Hobfoll, S. E., Halbesleben, J., Neveu, J.-P., \& Westman, M. (2018). Conservation of resources in the organizational context: The reality of resources and their consequences. Annual Review of Organizational Psychology and Organizational Behavior, 5(1), 103-128.

Ibrahim, S., Smith, P., \& Muntaner, C. (2009). A multi-group cross-lagged analyses of work stressors and health using canadian national sample. Social Science \& Medicine, 68(1), 49-59.

Johnson, D. R., \& Young, R. (2011). Toward best practices in analyzing datasets with missing data: Comparisons and recommendations. Journal of Marriage and Family, 73 (October), 926-945.

Keenan, E. M., \& Mostert, K. (2013). Perceived organizational support for strengths use The factorial validity and reliability of a new scale in the banking industry. South African Journal of Industrial Psychology, 39(1), 1-12.

Kim, M.-H., Kim, C.-K., Park, J.-K., \& Kawachi, I. (2008). Is precarious employment damaging to self-rated health? Results of propensity score matching methods, using longitudinal data in South Korea. Social Science \& Medicine, 67(12), 1982-1994.

Kirves, K., De Cuyper, N., Kinnunen, U., \& Nätti, J. (2011). Perceived job insecurity and perceived employability in relation to temporary and permanent worker's psychological symptoms: A two samples study. International Archives of Occupational and Environmental Health, 84(8), 899-909.

Klandermans, B., \& van Vuuren, T. (1999). Job insecurity. Special Issue of the European Journal of Work and Organizational Psychology, 8(2), 145-314.

Krohne, H. W. (2002). Stress and coping theories. International Encyclopedia of the Socia Behavioral Sciences, 22, 15163-15170.

Lazarus, R. S., \& Folkman, S. (1984). Stress, appraisal, and coping. Springer publishing company.

Lee, K. J., \& Carlin, J. B. (2017). Multiple imputation in the presence of non-normal data. Statistics in Medicine, 36, 606-617.

Luthans, F., \& Youssef, C. M. (2007). Emerging positive organizational behavior. Journal of Management, 33(3), 321-349.

McDowell, I. (2006). Measuring health: A guide to rating scales and questionnaires (3rd ed.) New York: Oxford University Press.

Metz, S. M., Wyrwich, K. W., Babu, A. N., Kroenke, K., Tierney, W. M., \& Wolinsky, F. D. (2007). Validity of patient-reported health-related quality of life global ratings of change using structural equation modeling. Quality of Life Research, 16(7), 1193-1202.

Mohr, G. B. (2000). The changing significance of different stressors after the announcement of bankruptcy: A longitudinal investigation with special emphasis on job insecurity. Journal of Organizational Behavior, 21(3), 337-359.

Morgeson, F. P., \& Humphrey, S. E. (2006). The Work Design Questionnaire (WDQ): developing and validating a comprehensive measure for assessing job design and the nature of work. Journal of applied psychology, 91(6), 1321.

Nielsen, I. K., Jax, S. M., \& Adams, G. A. (2000). Development and validation of scores on a two-dimensional workplace friendship scale. Educational and Psychological Measurement, 60(4), 628-643.

Peterson, C., \& Seligman, M. E. P. (2004). Character strengths and virtues: A handbook and classification. New York, NY: Oxford University Press.

Petrescu, M. J. (2013). Marketing research using single-item indicators in structural equation models. Journal of Marketing Analytics, 1(2), 99-117. https://doi.org/ 10.1057/jma.2013.7.

Podsakoff, P. M., MacKenzie, S. B., Lee, J. Y., \& Podsakoff, N. P. (2003). Common method biases in behavioral research: A critical review of the literature and recommended remedies. Journal of Applied Psychology, 88(5), 879-903.

Price, J. L. (1997). Handbook of organizational measurement. International Journal of Manpower, 18(4/5/6), 305-558.

Ragins, B. R., \& Dutton, J. E. (2007). Positive relationships at work: An introduction and invitation. In J. E. Dutton, \& B. R. Ragins (Eds.), Exploring positive relationships at work: Building a theoretical and research foundation (pp. 3-25). Mahwah, NJ: LawrenceErlbaumAssociates.

Ragu-Nathan, T. S., Tu, Q., Tarafdar, M., \& Ragu-Nathan, B. S. (2008). The consequences of technostress for end users in organizations: Conceptual development and empirical validation. Information Systems Research, 19(4), 417-433.

Richey, M. H., \& Richey, H. W. (1980). The significance of best-friend relationships in adolescence. Psychology in the Schools, 17(4), 536-540.
Riordan, C. M., \& Griffeth, R. W. (1995). The opportunity for friendship in the workplace: An underexplored construct. Journal of Business and Psychology, 10(2), 141-154.

Rodwell, L., Katherine, J. L., Romaniuk, H., \& Carlin, J. B. (2014). Comparison of methods for imputing limited-range variables: A simulation study. BMC Medical Research Methodology, 14, 57.

Røysamb, E., Tambs, K., Reichborn-Kjennerud, T., Neale, M. C., \& Harris, J. R. (2003). Happiness and health: Environmental and genetic contributions to the relationship between subjective well-being, perceived health, and somatic illness. Journal of Personality and Social Psychology, 85(6), 1136-1146.

Schaffer, B. S., \& Riordan, C. (2003). A review of cross-cultural methodologies for organizational research: A best-practices approach. Organizational Research Methods, 6(2), 169-215.

Seligman, M. E. P., Steen, T. A., Park, N., \& Peterson, C. (2005). Positive psychology progress: Empirical validation of interventions. American Psychologist, 60(5), 410-421.

Senf, K., \& Liau, A. K. (2013). The effects of positive interventions on happiness and depressive symptoms, with an examination of personality as a moderator. Journal of Happiness Studies, 14(2), 591-612.

Sias, P. M., \& Cahill, D. J. (1998). From coworkers to friends: The development of peer friendship in the workplace. Western Journal of Communication, 62(3), 273-300.

Sias, P. M., Heath, R. G., Perry, T., Silva, D., \& Fix, B. (2004). Narratives of workplace friendship deterioration. Journal of Social and Personal Relationships, 21(3), 321-340.

Sims, H. P., Szilagyi, A. D., \& Keller, R. T. (1976). The measurement of job characteristics. Academy of Management Journal, 19(2), 195-212.

Sluiter, J. K., De Croon, E. M., Meijman, T. F., \& Frings-Dresen, M. H. W. (2003). Need for recovery from work related fatigue and its role in the development and prediction of subjective health complaints. Occupational and Environmental Medicine, 60(suppl 1), i62-i70.

Solano, C. H. (1986). People without friends: Loneliness and its alternatives. Friendship and social interaction. In Derlega \& winstead (pp. 227-246). NY: Springer-Verlag.

Song, S.-H. (2006). Workplace friendships and employees' productivity: LMX theory and the case of the seoul city government. International Review of Public Administration, 11 (1), 47-58.

Soucek, R., \& Moser, K. (2010). Coping with information overload in email communication: Evaluation of a training intervention. Computers in Human Behavior, 26(6), 1458-1466.

Spreitzer, G. M. (1995). Psychological empowerment in the workplace: Dimensions, measurement, and validation. Academy of Management Journal, 38(5), 1442-1465.

Srivastava, S. C., Chandra, S., \& Shirish, A. (2015). Technostress creators and job outcomes: Theorising the moderating influence of personality traits. Information Systems Journal, 25(4), 355-401.

StataCorp. (2017). Stata statistical software: Release 15. College Station, TX: StataCorp LLC.

Synder, M., \& Smith, D. (1986). Personality and friendship: The friendship worlds of selfmonitoring. Friendship and social interaction. In Derlega and winstead (pp. 63-80). NY: Springer-Verlag.

Tabachnick, B. G., Fidell, L. S., \& Ullman, J. B. (2007). Using multivariate statistics (Vol 5). Boston, MA: Pearson.

Tarafdar, M., Cooper, C. L., \& Stich, J.-F. (2017). The technostress trifecta - techno eustress, techno distress and design: Theoretical directions and an agenda for research. Information Systems Journal, 29(1), 1-37.

Tarafdar, M., Pullins, E. B., \& Ragu-Nathan, T. S. (2015). Technostress - negative effect on performance and possible mitigations. Information Systems Journal, 25(2), $103-132$.

Tarafdar, M., Tu, Q., Ragu-Nathan, T. S., \& Ragu-Nathan, B. (2007). The impact of technostress on role stress and productivity. Journal of Management Information Systems, 24(1), 307-334.

Ten Brummelhuis, L. L., \& Bakker, A. B. (2012). A resource perspective on the workhome interface: The work-home resources model. American Psychologist, 67(7), 545-546.

Tokuno, K. A. (1986). The early adult transition and friendships: Mechanisms of support. Adolescence, 21(83), 593-606.

Virtanen, P., Janlert, U., \& Hammarström, A. (2011). Exposure to temporary employment and job insecurity: A longitudinal study of the health effects. Occupational and Environmental Medicine, 68(8), 570-574.

Wang, K., Shu, Q., \& Tu, Q. (2008). Technostress under different organizational environments: An empirical investigation. Computers in Human Behavior, 24(6), 3002-3013.

Ware, J. E., Jr., \& Gandek, B. (1998). Overview of the SF-36 health survey and the international quality of life assessment (IQOLA) project. Journal of Clinical Epidemiology, 51(11), 903-912.

Weil, M. M., \& Rosen, L. D. (1997). Technostress: Coping with technology@WORK @HOME @PLAY. New York: John Wiley \& Sons.

Weiss, R. (1974). The provisions of social relationships. In Z. Rubin (Ed.), Doing unto others (pp. 17-22). Englewood Cliffs, NJ: Prentice Hall.

White, I. R., Royston, P., \& Wood, A. M. (2010). Multiple imputation using chained equations: Issues and guidance for practice. Statistics in Medicine, 30(4), 377-399.

Wiezer, N., Nielsen, K., Pahkin, K., Widerszal-Bazyl, M., De Jong, T., Mattila-Holappa, P., et al. (2011). Exploring the link between restructuring and employee well-being. Warsaw: Central Institute for Labour Protection-National Research Institute.

Tuomi, K., Ilmarinen, J., Jahkola, A., Katajarinne, L., \& Tulkki, A. (1998). Work Ability Index (2nd Edition). Helsinki: Finnish Institute of Occupational Health.

van Woerkom, M., Bakker, A. B., \& Nishii, L. H. (2016). Accumulative job demands and support for strength use: Fine-tuning the job demands-resources model using conservation of resources theory. Journal of Applied Psychology, 101(1), 141-150. 
Wood, A. M., Linley, P. A., Maltby, J., Kashdan, T. B., \& Hurling, R. (2011). Using personal and psychological strengths leads to increases in well-being over time: A longitudinal study and the development of the strengths use questionnaire. Personality and Individual Differences, 50(1), 15-19.
World Health Organization, Garcia, P., \& McCarty, M. (2010). Measuring health. A step in the development of city health profiles. Copenhagen: World Health Organization Regional Office for Europe.

Wurm, S., Tomasik, M. J., \& Tesch-Römer, C. (2008). Serious health events and their impact on changes in subjective health and life satisfaction: The role of age and a positive view on ageing. European Journal of Ageing, 5(2), 117-127. 